\title{
Credit Risk Transfer and Bank Insolvency Risk
}

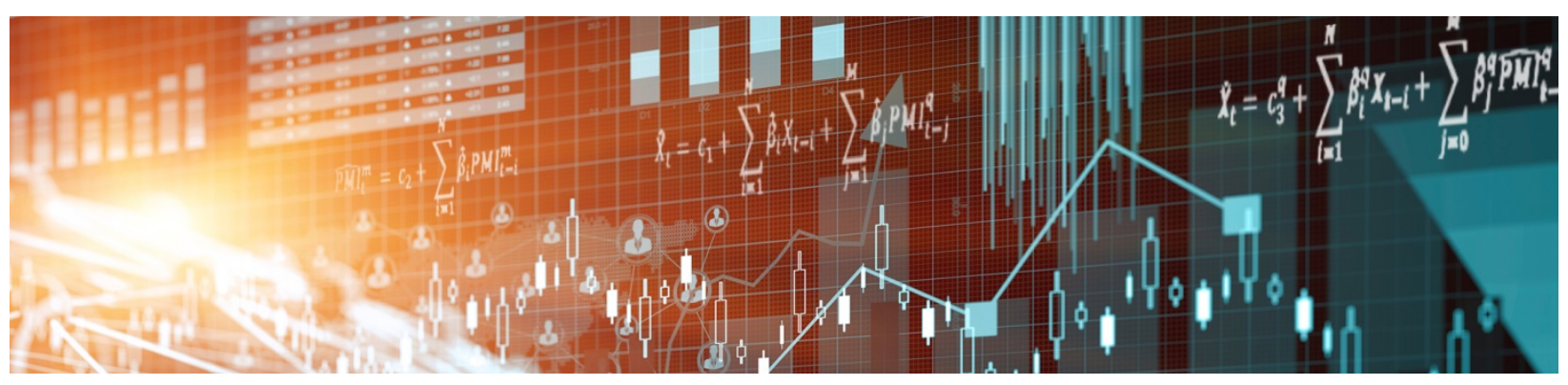

by Maarten R. C. van Oordt 
Bank of Canada Staff Working Paper 2017-59

December 2017

\title{
Credit Risk Transfer and Bank Insolvency Risk
}

\author{
by
}

\author{
Maarten R. C. van Oordt \\ Financial Stability Department \\ Bank of Canada \\ Ottawa, Ontario, Canada K1A 0G9 \\ mvanoordt@bankofcanada.ca
}




\section{Acknowledgements}

Thanks are due to Toni Ahnert and Yu Zhu, and participants in the Federal Reserve Bank of Atlanta conference "Financial Regulation: Fit for the Future?” (Atlanta, 2017), and participants in presentations at the Bank of Canada (Ottawa, 2017), De Nederlandsche Bank (Amsterdam, 2017) and the Central Bank of Ireland (Dublin, 2017) for helpful comments and suggestions. Views expressed do not necessarily reflect those of the Bank of Canada. 


\begin{abstract}
The present paper shows that, everything else equal, some transactions to transfer portfolio credit risk to third-party investors increase the insolvency risk of banks. This is particularly likely if a bank sells the senior tranche and retains a sufficiently large firstloss position. The results do not rely on banks increasing leverage after the risk transfer, nor on banks taking on new risks, although these could aggravate the effect. High leverage and concentrated business models increase the vulnerability to the mechanism. These results are useful for risk managers and banking regulation. The literature on credit risk transfers and information asymmetries generally tends to advocate the retention of 'information-sensitive' first-loss positions. The present study shows that, under certain conditions, such an approach may harm financial stability, and thus calls for further reflection on the structure of securitization transactions and portfolio insurance.
\end{abstract}

Bank topics: Credit risk management; Financial institutions; Financial stability JEL codes: G21, G28, G32

\title{
Résumé
}

La présente étude montre que, toutes choses égales par ailleurs, certaines opérations de transfert, à des tiers investisseurs, du risque de crédit du portefeuille titrisé accroissent le risque d'insolvabilité des banques, ce qui est particulièrement vrai si les banques cèdent la tranche prioritaire et conservent une position de premières pertes suffisamment importante. Les résultats obtenus ne tiennent pas compte du fait que le transfert du risque pourrait être suivi d'une augmentation du levier financier ou d'une prise de risque accrue, bien que ces comportements puissent accentuer le phénomène. Un levier financier élevé et un modèle d'entreprise axé sur la spécialisation augmentent la vulnérabilité inhérente au mécanisme. Ces constats présentent un intérêt certain pour les gestionnaires de risques et les autorités de réglementation bancaire: la littérature sur le transfert du risque de crédit et les asymétries d'information tend à préconiser la conservation des positions de premières pertes "sensibles à l'information ». La présente étude établit que, lorsque certaines conditions sont réunies, cette approche peut avoir des effets néfastes sur la stabilité financière. Ses conclusions invitent à une réflexion plus approfondie sur la structure des opérations de titrisation et sur l'assurance de portefeuille.

Sujets : Gestion du risque de crédit; Institutions financières; Stabilité financière

Codes JEL : G21, G28, G32 


\section{Non-technical summary}

Credit risk transfer is an important tool for banks to manage their exposure to credit risk. Credit risk transfer can take many different forms, such as credit portfolio insurance, loans sales, securitization and the use of derivatives to hedge credit risk. These instruments do not make credit risk magically disappear, but they can be used by banks to reduce their exposure by transferring some of the credit risk to third-party investors.

Often, it is presumed that, everything else equal, a reduction in exposure to credit risk results in a 'safer' bank, i.e., a bank that is less likely to become insolvent. An example is that capital adequacy regulation generally allows banks to finance loan portfolios with less capital if they are partially hedged or insured. The present paper assesses - for different transaction structures - how a credit risk transfer affects the bank's insolvency risk. One result is that, contrary to popular belief, some transactions that reduce the exposure of banks to credit risk do in fact increase the probability of bank insolvency.

Whether this holds true depends on both the structure of the transaction and several bank-specific factors. The insolvency risk of a bank may especially increase if transactions are structured in such a manner that banks transfer the risk in a senior position and retain the risk in a sufficiently large first-loss position. A bank-specific factor that is particularly important is the (unweighted) capital ratio of a bank. Everything else equal, transactions that reduce the insolvency risk of banks with high capital ratios may increase the insolvency risk of banks with weaker capital positions. Moreover, for diversified banks, past transactions to transfer credit risk may turn out to be harmful when other business lines perform poorly.

The present study provides risk managers and supervisors with some guidance on how to test whether transactions to transfer credit risk are expected to reduce or increase insolvency risk of a bank. This assessment depends on a number of parameters, which are relatively straightforward to calibrate. Importantly, the approach does not need a sophisticated model to estimate credit risk, because it makes very minimal assumptions on the statistical distribution of credit losses. A downside is that the method will not provide a conclusive answer in each and every situation. In such situations, risk managers can resort to simulations instead. 


\section{Introduction}

Credit risk transfer is an important tool for banks to manage their exposure to credit risk. Credit risk transfer can take many different forms, such as credit portfolio insurance, loans sales, securitization and the use of derivatives to hedge credit risk. These instruments do not make credit risk disappear, but they can be used by banks to reduce their exposure by transferring some of the credit risk to third-party investors.

This paper studies the direct impact of credit risk transfer to remove credit risk from the balance sheets of financial institutions on their insolvency probabilities. 'Direct' impact here refers to the change in the insolvency risk as a result of the transfer of credit risk to thirdparty investors, holding everything else equal. This paper focuses on deriving some results that can help risk managers and supervisors evaluating whether a credit risk transfer to thirdparty investors reduces or increases the insolvency probability of a financial institution, even if no sophisticated model to estimate credit risk is available.

Often, it is presumed that, everything else equal, a reduction in exposure to credit risk results in a 'safer' bank, i.e., a bank that is less likely to become insolvent. The possibility of higher insolvency risk as a consequence of removing credit risk from the balance sheet may sound counterintuitive, because such a credit risk transfer removes some of the 'overall uncertainty' of the institution's cash flow. However, a reduction in 'overall uncertainty' of a bank's cash flow does not necessarily imply a smaller probability of insolvency for that institution. The reason is straightforward. Credit risk transfer to third-party investors may improve the bank's position if the risk materializes. But, since such protection is not free, ex post, the bank will be worse off in all other states of the world. If credit risk transfer isolates risks from the balance sheet that materialize only after a bank fails, such credit risk protection will not provide benefits in terms of avoiding bank insolvencies. On the contrary, the cost of credit risk protection will increase the minimum return (before the cost of protection) necessary to stay solvent. The results suggest that such a counterintuitive outcome may hold true for some commonly applied credit risk transfer strategies. Moreover, 
the paper shows that the magnitude of the effect in terms of capital can be considerable using a numerical example.

Interest expenses on bank debt may drop in response to an overall reduction in the uncertainty of a bank's cash flows. Such a reduction in debt servicing costs can attenuate a potentially harmful direct impact of credit risk transfer on the bank's insolvency probability. One may suspect that such a benefit could outweigh the harmful direct impact if the bank's funding costs were to fall sufficiently. However, our results show this does not hold true if depositors, in spite of deposit insurance, fully appreciate the reduction in the risk of the bank's cash flow, and if credit risk protection is fairly priced. The intuitive reason is that the cost of credit risk protection will be footed to depositors if the bank fails. Hence, the bank's cost of borrowing may decrease in response to more credit risk protection, but this decrease is not expected to reflect the full cost of credit risk protection.

Our results show that strategies where banks reduce exposures but retain a sufficiently large first-loss exposure are particularly susceptible to a potential increase in insolvency risk. Despite this adverse impact on banks' insolvency risk, such credit risk transfer strategies often receive some sort of favorable treatment. One example is the regulation on credit risk retention, which provides a more favorable regulatory treatment of securitizations in which banks retain the equity tranches. Another example is the government facilitating or providing forms of portfolio insurance if banks retain a first-loss position. A third example is the case where capital requirements provide capital relief on an insured portfolio, if an institution insures losses beyond a certain amount. In the latter case, the credit risk transfer may even have a twofold harmful impact on the bank solvency by increasing insolvency risk not only because of the direct impact of the credit risk transfer, but also as a consequence of smaller capital buffers in response to a lower requirement. In each of these examples, a poorly calibrated credit risk transfer can increase the probability of bank insolvencies.

Whether credit risk transfer increases banks' insolvency risk depends on several factors. One factor is the leverage of a bank. Banks operating with higher leverage need to meet a higher minimum return on their assets to be able to meet their debt obligations. Designing a 
credit risk transfer that helps the bank to meet a higher threshold can be more challenging. Therefore, the weaker the capital position of a bank, the more likely it is that credit risk transfer will increase the insolvency risk of a bank.

A second factor is the size of the exposures in the junior and senior positions, i.e., the maximum amount of losses incurred by investors in the first-loss position before losses are incurred in the senior position. In particular, it is important how the size of the junior and senior positions compare with the minimum return that a bank needs to be able to meet its debt obligations. For example, if a specialized bank transfers the risk of a senior position in a loan portfolio, and the guaranteed return on the portfolio after the cost of credit risk protection is less than the payoff promised to the bank's depositors, then it is very likely that this credit risk transfer will increase the insolvency risk of the bank.

A third factor is the degree of concentration of the banks' business models. The direction of the impact is particularly clear for banks with more concentrated business models. For diversified institutions, the direction of the impact of a credit risk transfer can be more of a challenge. The reason is that banks may reap benefits from diversification, as they receive income from other sources, as well as suffer additional losses, when risks from other exposures materialize. Such variation changes the minimum return that the bank needs to earn on the loan portfolio for which the credit risk is transferred.

The analysis reveals a potential perilous interaction between diversification and the impact of credit risk transfers, which may pose a challenge for risk managers in practice. The source of this interaction is that a credit risk transfer can be beneficial in terms of insolvency risk when other business lines of the bank perform well, while the same credit risk transfer may turn out to be harmful when other business lines perform poorly. The mechanism is that a weak performance of other business lines will increase the minimum return on the insured loan portfolio necessary to stay solvent. Hence, a credit risk transfer that would be beneficial for the bank's insolvency risk under normal conditions, because it guarantees a return that is sufficiently high under normal conditions, could result in a return that is too low when other business lines perform poorly. As a consequence, bank insolvencies may occur 
that could have been avoided either if the bank had diversified without engaging in a credit risk transfer, or if the bank had engaged in the credit risk transfer without diversification.

The results in this paper do not rely on a particular form of the distribution function of potential losses on loan portfolios. This is an attractive feature, because the risk profiles of the retained tranches can be highly dependent on distributional assumptions. However, as a consequence, the results have less to say about the direction of the impact if the insured risk represents only a small portion of the balance sheet. In those cases, proving the beneficial impact of credit risk transfer may require additional analysis, which can be based on simulations.

The present paper focuses on the direct impact of a credit risk transfer, i.e., the impact holding everything else equal. Except when the analysis considers endogenous funding costs, the impact can be considered as mechanistical. In addition to this mechanistical direct impact, there can be further indirect impacts of credit risk transfer. These include, for example, the impact of credit risk transfer on subsequent investment or risk management decisions at banks, or macroeconomic or system-wide consequences of credit risk transfer that are not taken into account by risk managers at individual banks.

Several theoretical studies suggest that such indirect impacts of credit risk transfer can be harmful for bank stability. In those studies, the combination of a positive direct impact and a negative indirect impact can result in a net negative effect on bank stability. For example, Wagner and Marsh (2006) show that credit risk transfer improves the risk-return trade-off for banks because it facilitates diversification of their investments. However, as a consequence, banks increase the level of leverage. Hence, the 'overall' impact could be either more or less stability. Similarly, Wagner (2007) argues that enhanced liquidity of bank assets as a consequence of credit risk transfer techniques makes banks safer. However, as banks optimally increase their exposure in response to the enhanced liquidity, the overall impact on stability may be negative. In the model of Allen and Carletti (2006), the direct impact of credit risk transfer from the banking to the insurance sector is an improvement in risk sharing. However, the indirect impact is an increase in contagion risk, because insurers 
who liquidate safe long-term assets when adverse shocks materialize change the risk profile of these assets, resulting in potential mark-to-market losses at banks. Another example is the study of Shin (2009), which emphasizes that securitization, as a form of credit risk transfer, facilitates a system-wide credit expansion, which could promote financial instability through lower lending standards. The present study contributes to this literature by showing that, depending on the transaction structure, even the direct impact of transactions can be negative for bank insolvency risk.

The present paper is related to Van Oordt (2014), who focuses on whether risk sharing among financial institutions through the exchange of tranches in securitizations enhances financial stability. In such a risk-sharing model, all credit risk remains in the financial sector. Hence, from an individual bank's perspective, the credit risk transfer not only reduces initial exposures, but also results in new exposures. Securitization may then both stabilize or destabilize the financial sector depending on the design of the tranches. These results complement those of Shaffer (1994) and Wagner (2010), who show that linear risk sharing within the financial system increases joint failure risk. In contrast to Van Oordt (2014), the present paper studies the effect of credit risk transfer on the stability of banks if credit risk is transferred to third-party investors.

\section{$2 \quad$ Related Literature}

\section{$2.1 \quad$ Theoretical}

Transactions involving credit risk transfers have many attributes, including the portion of risk retained by the bank. ${ }^{1}$ The design of transactions to adequately address concerns as a consequence of information asymmetries has been a flourishing topic of theoretical research on credit risk transfers. One general recommendation is to construct and transfer the risk in 'information insensitive' tranches, i.e., securities whose payoffs are little affected by pri-

\footnotetext{
${ }^{1}$ The current paper is not directly related to papers on transactions in which the bank retains all credit risk (e.g., securitization with recourse); see, e.g., Benveniste and Berger (1987) for an early study on this topic. Banks would, in principle, not incur a cost of credit risk protection in such a transaction.
} 
vate information, and retain the 'information sensitive' tranches; see, e.g., Greenbaum and Thakor (1987), Pennacchi (1988), Gorton and Pennacchi (1990, 1995), Boot and Thakor (1993), Riddiough (1997), DeMarzo and Duffie (1999) and DeMarzo (2005). Usually, the 'information insensitive' tranches are the most senior tranches, although this need not necessarily hold true in each and every situation; see, e.g., Chiesa (2008). The effect of credit risk transfer on bank insolvency risk receives little attention in this strand of literature, although some studies mention the impact on the stability of banks as a "productive area for future research;" see, e.g., Pennacchi (1988, p. 393).

Some of the more recent studies on information asymmetries in credit risk transfer have focused on implications for mandatory retention regulation. Kiff and Kisser (2014) suggest that without retention requirements, ineffective retention schedules may prevail if banks have incentives to economize on capital. They suggest regulators could opt to impose equity tranche retention to better align incentives. Guo and $\mathrm{Wu}(2014)$ point out that mandatory retention requirements may undermine the possibility to signal the quality of underlying assets by voluntary risk retention. Fender and Mitchell (2009) and Cerasi and Rochet (2014) prove the retention of mezzanine tranches to be more effective in aligning incentives in certain cases. The reason is that losses as a result of, for example, adverse macroeconomic conditions could entirely wipe out the equity tranches. Pagès (2013) explores how optimal retention schemes can be implemented in potentially more cost-effective ways. In general, these studies recommend a flexible design of retention regulation in recognition of the variation in risk characteristics of securitized assets and the differences in economic conditions.

\subsection{Empirical}

Empirical studies tend to focus more on the default risk of the underlying loans than on the

insolvency risk of the issuer. Several studies that discuss the empirical relation between risk of institutions and credit risk transfer are discussed below. However, it should be kept in mind that those studies generally do not disentangle the direct impact of credit risk transfer 
on insolvency risk and the aforementioned indirect impacts as a consequence of changes to risk management practices and investment decisions at banks.

Cebenoyan and Strahan (2004) document that banks that actively buy and sell loans on the secondary markets tend to have lower risk-weighted capital ratios. Similarly, Casu et al. (2013) observe that securitizing banks have lower capital ratios on average. However, they do not find evidence of a significant impact on the performance of first-time securitizers when compared with a matched sample of banks that do not securitize. Le et al. (2016) document securitizing banks to be more risky using several accounting-based measures, such as the ratio of non-performing loans, the loan loss allowance and charge-offs. ${ }^{2}$ Sarkisyan and Casu (2013) assess the impact of securitization on the Z-scores of issuing bank holding companies in the US. They document lower Z-scores if issuing banks retain larger interests, which suggests a positive relation with bank failure risk, a finding that is in line with the expected theoretical relation.

Franke and Krahnen (2007) document evidence that post-announcement systematic risk, as measured by market betas, is higher for banks using collateralized debt obligations to transfer risks to market participants. Similarly, Uhde and Michalak (2010) report that securitization tends to increase systematic risk of banks. Trapp and Weiß (2016) document higher measures of downside tail risk, such as Marginal Expected Shortfall and $\Delta$ CoVaR for banks involved in securitization.

Interestingly, there is some limited evidence that the relation between credit risk transfer and bank risk depends on the capital position of banks. Lockwood et al. (1996) observe that systematic risk, as measured by market betas, does increase upon announcement of securitization transactions for banks with weaker capital positions, while a reduction in risk is observed for banks with stronger capital positions. ${ }^{3}$ Such a twofold relation is consistent with our theoretical result that whether credit risk transfer increases or decreases insolvency risk crucially depends on how prices and the retained interest relate to the level of capital

\footnotetext{
${ }^{2}$ Simulation results of Chang and Chen (2016) suggest that insolvency risk is negatively related to credit risk transfer if the bank acts as a protection buyer, and positively if it acts as a protection seller.

${ }^{3}$ Similarly, Thomas (2001) observes that securitizers with stronger capital positions tend to have higher excess returns on issuance date of securitizations.
} 
ratio of a bank. For example, a strategy of selling senior claims on a credit portfolio is harmful in terms of insolvency risk if the retained first-loss position is relatively large compared with the capital ratio.

\section{Model Setup}

We consider a one-period model with a bank holding a unit investment financed with deposits, $d$, and equity, $1-d$. An overview of the balance sheet is provided in Figure 1. At the start of the period, the bank holds investments $\omega$ in asset $X$ and $(1-\omega)$ in asset $Y$. Asset $X$ is the loan pool for which the firm considers transferring the credit risk to thirdparty investors. Asset $Y$ represents the pool with all other investments of the firm. The assets generate end-of-period cash flows denoted by $x$ and $y$. The originator operates in a perfect information world. The only uncertainty is the end-of-period realization $(x, y)$. The density of the continuous joint distribution function is denoted as $\phi(x, y)$ with full support $[0, \bar{x}] \times[\underline{y}, \bar{y}]$.

At the start of the period, the firm transfers credit risk of fraction $r \in[0,1]$ of its position in asset $X$ using credit risk transfer strategy $(i, k)$. Credit risk transfer can take three different forms, i.e., the form of transferring the risk of a senior position, the risk of a junior (first-loss) position, or a full risk transfer, which are denoted as $i \in\{s, j, f\}$, respectively. For $i=j$, the firm exchanges the end-of-period cash flow $s^{s}(x, k)=\min \{x, k\}$ with third-party investors against a unit price $p(k)$. If $i=s$, the firm exchanges the cash flow $s^{j}(x, k)=\max \{x-k, 0\}$ against a unit price $q(k)$. If $i=f$, third-party investors obtain both cash flows for a price $p(k)+q(k) .{ }^{4}$ Proceeds are invested against the risk-free rate, which we

\footnotetext{
${ }^{4}$ The level of $p(k)+q(k)$ is independent of threshold $k$ if the law of one price holds true, since $s^{s}(x, k)+$ $s^{j}(x, k)=x$ for any $k$. If the law of one price does not hold true, then the issuing firm could optimally choose $k$ to maximize the proceeds from the credit risk transfer. For our results it is irrelevant whether the law of one price holds true.
} 
Figure 1: Balance sheet and credit risk transfer in the model
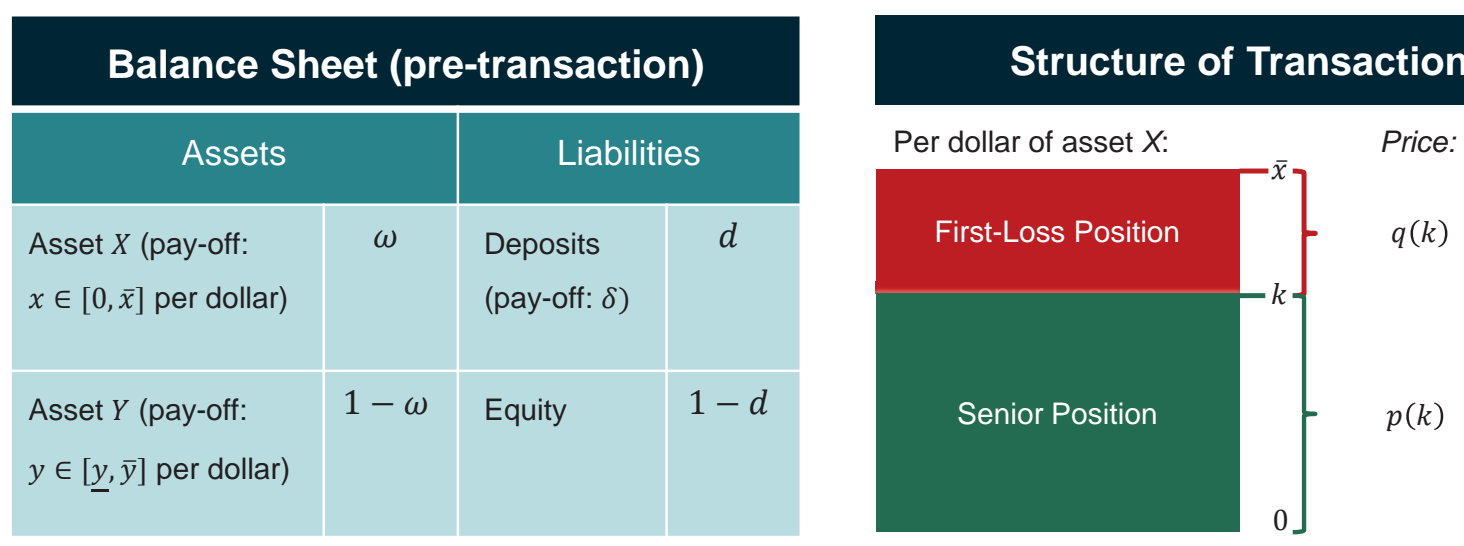

Note: The figure summarizes the model information on the bank's balance sheet before the credit risk transfer and the potential structure of the transaction.

normalize to zero. Hence, the end-of-period cash flow of the firm, $v_{i, k}(x, y, r)$, equals

$$
\begin{aligned}
v_{i, k}(x, y, r)= & \omega x+(1-\omega) y+ \\
& +r \omega\left[\mathbf{1}_{i \in\{s, f\}}\left(p(k)-s^{s}(x, k)\right)+\mathbf{1}_{i \in\{j, f\}}\left(q(k)-s^{j}(x, k)\right)\right] .
\end{aligned}
$$

This setup is sufficiently flexible to cover various forms of credit risk transfer. One interpretation is securitization, where the bank sells senior and/or junior tranches in the securitized loan portfolio $X$. A second interpretation is where the bank buys credit portfolio insurance for $X$. If the bank retains the junior tranche, it would be comparable to insuring the returns on $X$ with a deductible $\bar{x}-k$ against a premium $k-p(k)$. The transfer of the risk in the junior position could be considered as insuring the returns on $X$ against a premium $\bar{x}-k-q(k)$ with an insurance coverage limit of $\bar{x}-k$. A third interpretation is that the bank uses credit derivatives to hedge portfolio risk.

Insolvency occurs if the end-of-period cash flow $v_{i, k}(x, y, r)$ is insufficient to repay the depositors the amount $\delta_{i, k}(r)$, where the $\delta_{i, k}(r)$ represents the principal amount and interest owed to depositors. The level of this solvency threshold in the absence of credit risk transfer is denoted as $\delta_{i, k}(0)=\delta$ for any $(i, k)$. In other words, the probability of insolvency with 
credit risk transfer strategy $i$ equals

$$
\pi_{i, k}(r)=\operatorname{Pr}\left[v_{i, k}(x, y, r)<\delta_{i, k}(r)\right]
$$

Our intention is to assess how different credit risk transfer strategies affect the level of $\pi_{i, k}(r)$.

With the threshold return $x_{i}^{*}(y, r)$ denoting the minimum level of $x$ such that $v_{i, k}(x, y, r) \geq \delta_{i, k}(r)$, the probability of insolvency can be obtained from evaluating the double integral

$$
\pi_{i, k}(r)=\int_{0}^{\infty} \int_{0}^{x_{i, k}^{*}(y, r)} \phi(x, y) \mathrm{d} x \mathrm{~d} y .
$$

Comparing the levels of $\pi_{i, k}(r)$ and $\pi_{i, k}(0)$ reveals whether credit risk transfer strategy $(i, k)$ is beneficial or harmful in terms of insolvency risk of the originator, where $\pi_{i, k}(0)$ can be obtained from evaluating (3) with

$$
x_{i, k}^{*}(y, 0)=\delta+\frac{1-\omega}{\omega}(\delta-y) .
$$

One important challenge is that evaluating (3) requires an accurate approximation of the return distribution $\phi(x, y)$. However, it is well known that the return distributions of junior and senior positions in credit portfolios strongly depend on the dependence structure among loan defaults and the likelihood of tail events; see, e.g., Duffie et al. (2009) and Gennaioli et al. (2012). Hence, one may suspect that the conclusions may strongly depend on the underlying assumptions regarding the specification of $\phi(x, y)$. In other words, results based on evaluating (3) using simulations or an analytical solution may be subject to debate. Instead, we will focus on deriving results that apply to any continuous $\phi(x, y)$ with full support $[0, \bar{x}] \times[\underline{y}, \bar{y}]$. 


\section{Results}

It is not necessary in every situation to specify $\phi(x, y)$ to evaluate the effect of a credit risk transfer on insolvency risk. The reason is that one can directly compare the levels of the solvency threshold returns $x_{i, k}^{*}(y, r)$ and $x_{i, k}^{*}(y, 0)$. If $x_{i, k}^{*}(y, r) \leq x_{i, k}^{*}(y, 0)$ for every $y \in[\underline{y}, \bar{y}]$, then it must hold true that $\pi_{i, k}(r) \leq \pi_{i, k}(0)$ : The credit risk transfer reduces insolvency risk. Similarly, if $x_{i, k}^{*}(y, r) \geq x_{i, k}^{*}(y, 0)$ for every $y \in[\underline{y}, \bar{y}]$, then it must hold true that $\pi_{i, k}(r) \geq \pi_{i, k}(0)$ : The credit risk transfer increases insolvency risk. Finally, if $x_{i, k}^{*}(y, r)<x_{i, k}^{*}(y, 0)$ for some levels of $y \in[\underline{y}, \bar{y}]$, and $x_{i, k}^{*}(y, r) \geq x_{i, k}^{*}(y, 0)$ for some other levels of $y \in[\underline{y}, \bar{y}]$, then the direction of the impact of the credit risk transfer on $\pi_{i, k}$ will be indeterminate without further specifying $\phi(x, y)$.

\subsection{Exogenous Funding Costs}

We start our analysis from the point of view of a specialized bank $(\omega=1)$ with risk-insensitive funding costs for illustrative purposes. This stacks the cards in favour of our approach, because the level of $x_{i, k}^{*}(y, r)$ does not depend on $y$ in this case. ${ }^{5}$ The following proposition summarizes the effect of a credit risk transfer on the insolvency risk of a specialized firm.

Proposition 1 Credit risk transfer reduces the probability of insolvency of a specialized bank with exogenous funding costs if

1. $p(k) \geq \delta$ in the case of transferring the risk in a senior position;

2. $p(k)+q(k) \geq \delta$ in the case of a full risk transfer;

3. $k+q(k) \geq \delta$ in the case of transferring the risk in a junior position.

Otherwise, credit risk transfer strictly increases the probability of insolvency.

Proof. See Appendix.

\footnotetext{
${ }^{5}$ If $\omega=1$, then we have $\partial x_{i, k}^{*}(y, r) / \partial y=0$ and $\partial x_{i, k}^{*}(y, 0) / \partial y=0$ by construction. As a consequence, it is impossible to have $x_{i, k}^{*}(y, r)<x_{i, k}^{*}(y, 0)$ for some levels of $y \in[\underline{y}, \bar{y}]$ and $x_{i, k}^{*}(y, r) \geq x_{i, k}^{*}(y, 0)$ for some other levels of $y \in[\underline{y}, \bar{y}]$. Hence, our approach always provides an answer in this case.
} 
Why can a reduction in the 'overall risk' increase the insolvency risk of the firm? In the case of a full risk transfer, the reason is obvious. In the context of a specialized bank, selling both tranches means, in effect, the liquidation of the firm. If the liquidation value of $X$ is insufficient to repay creditors, i.e., if $p(k)+q(k)<\delta$, selling both tranches effectively eliminates the chance of survival when a high return materializes. The credit risk transfer is the inverse of 'gambling for resurrection.'

If the firm retains the risk in the senior position, the reason is similar, but the constraint is weaker. It will always be possible to design some credit risk transfer such that $\delta \leq k<\bar{x}$, which implies $\delta<k+q(k)$, as long as the best possible outcome exceeds the insolvency threshold, i.e., $\bar{x}>\delta$. Hence, even if the liquidation value of $X$ is insufficient to repay creditors, then it will still be possible to reduce the probability of insolvency of the bank by transferring some of the upward potential. However, transferring risk in a junior position increases the insolvency probability if $k+q(k)<\delta$. In this case, the proceeds from the transfer will be insufficient to repay depositors, even if the retained senior position yields the full pay-off $k$.

The strongest constraint in Proposition 1 to determine whether the removal of credit risk has a beneficial effect is the one regarding the case where the bank retains the firstloss position. However, the reason why insolvency risk may increase in this case is more subtle. Proposition 1 implies that unless the retained first-loss position is sufficiently thin, transferring the risk in the senior position must increase the probability of insolvency. This is because of the following reason. Transferring credit risk in a senior position can be considered as protecting the bank against realizations of the (tail) events where $x<k$. This protection comes at a premium, $k-p(k)$. However, the end-of-period cash flow of a protected bank will be insufficient to achieve solvency if the insured risk materializes under the condition in the proposition, because $p(k)<\delta$. Hence, insolvencies are not avoided. On the contrary, the transfer increases the insolvency risk of the firm, because the cost of the credit risk protection raises the minimum return necessary to remain solvent above the original level. 
Proposition 1 shows that whether a credit risk transfer is beneficial or harmful in terms of insolvency risk depends on whether the insolvency threshold of the specialized firms, $\delta$, is sufficiently low. Parameter $\delta$ is positively related to the leverage of a bank. It follows that a certain credit risk transfer may be beneficial in terms of insolvency risk for a well-capitalized issuer, while the same transaction could be harmful for an issuer with a more fragile financial structure, i.e., a higher $\delta$. The more leveraged a bank is, the more likely it is that a credit risk transfer will be harmful in terms of insolvency risk.

Note that the direction of the impact is independent of the scale of transactions: The direction of the effect in Proposition 1 is independent of $r$. Of course, this does not apply to the magnitude of the effect, which will increase in the scale of the transaction.

In a similar fashion, the following lemma describes how credit risk transfers affect the insolvency risk of a bank that also invests in a portfolio of other assets, $Y$, for a given realization $y$.

Lemma 1 Given some realization y, the credit risk transfer reduces the probability of insolvency of a bank with exogenous funding costs if

1. $p(k) \geq x_{i, k}^{*}(y, 0)$ in the case of transferring the risk in a senior position;

2. $p(k)+q(k) \geq x_{i, k}^{*}(y, 0)$ in the case of a full risk transfer;

3. $k+q(k) \geq x_{i, k}^{*}(y, 0)$ in the case of transferring the risk in a junior position.

Otherwise, credit risk transfer strictly increases the probability of insolvency.

The mechanics behind this lemma are exactly the same as those described above, with the only difference that the ex-post realization of $y$ will change the threshold that determines whether a credit risk transfer reduces or increases the bank's insolvency risk. Hence, uncertainty regarding the ex-post return on the bank's other investments leads to uncertainty regarding the question whether a credit risk transfer reduces bank insolvency risk.

Lemma 1 exposes a potentially poisonous interaction between the benefits of diversification and the impact of credit risk transfers. Suppose that a credit risk transfer would reduce 
bank insolvency risk if the performance of $Y$ is in accordance with expectations. Then we have that this credit risk transfer will certainly reduce bank insolvency risk if $y$ is higher than expected, because it is associated with a lower threshold for beneficial credit risk transfers $x_{i, k}^{*}(y, 0)$ in Lemma 1; see Eq. (4). However, the same credit risk transfer strategy may turn out to increase bank insolvency risk in case of a lower than expected realization of $y$, because a lower $y$ leads to a higher threshold $x_{i, k}^{*}(y, 0)$. Hence, the credit risk transfer will be beneficial when the firm also benefits from profits due to diversification in $Y$, while the credit risk transfer may turn out to be harmful when the bank is in poor condition because losses on the diversified position $Y$ materialize. This interaction between the benefits of the two different risk management strategies, i.e., diversification and credit risk protection, may pose a challenge for risk managers in practice.

Asset $Y$ could be a risk-free asset (i.e., $y=\underline{y}=\bar{y}$ ). If $Y$ is a risk-free asset, then Lemma 1 will directly answer the question of whether the credit risk transfer reduces or increases bank insolvency risk. With variation in the bank's return on the investment in $Y$, one can still be certain about the direction of the impact if Lemma 1 provides the same answer for any $y \in[\underline{y}, \bar{y}]$. However, the larger the risk in terms of $(\bar{y}-\underline{y})$ and the degree of diversification in terms of $(1-\omega)$, the more limiting this will be for determining the direction of the effect of credit risk transfers on bank insolvency risk without explicit assumptions regarding $\phi(x, y)$.

This is shown in the following propositions. The first proposition gives the condition under which a credit risk transfer strategy is beneficial in terms of insolvency risk.

Proposition 2a Credit risk transfer strictly reduces the insolvency probability of a firm with exogenous funding costs if

1. $p(k)>\bar{\delta}$ in the case of transferring the risk in a senior position;

2. $p(k)+q(k)>\bar{\delta}$ in the case of a full risk transfer;

3. $k+q(k)>\bar{\delta}$ in the case of transferring the risk in a junior position, where $\bar{\delta}=\delta+\frac{1-\omega}{\omega}(\delta-\underline{y})$. 


\section{Proof. See Appendix.}

The proposition replaces the $\delta$ in Proposition 1 by $\bar{\delta}$. The $\bar{\delta}$ depends on the original insolvency threshold and a layer of uncertainty which is an increasing function of $\delta-\underline{y}$. The magnitude of $\delta-\underline{y}$ is the maximum shortfall in the return on $Y$ relative to the firm's overall insolvency threshold. The larger the magnitude of this downside risk, the less likely it is that one can be certain that a credit risk transfer reduces the insolvency probability. For lower realizations of $y$, the firm needs a higher realization of $x$ to stay solvent. In other words, diversification raises the threshold that determines whether credit risk transfer strategies are beneficial in terms of insolvency risk for lower values of $y$. If the magnitude of the downside risk is sufficiently large, then there will exist contingencies in which the credit risk transfer will be harmful in terms of insolvency risk, which implies that the insolvency risk of the bank will depend on the functional form of $\phi(x, y)$.

Similarly, the following proposition gives the condition under which a credit risk transfer strategy is harmful in terms of insolvency risk.

Proposition $2 \mathrm{~b}$ Credit risk transfer strictly increases the insolvency probability of a firm with exogenous funding costs if

1. $p(k)<\underline{\delta}$ in the case of transferring the risk in a senior position;

2. $p(k)+q(k)<\underline{\delta}$ in the case of a full risk transfer;

3. $k+q(k)<\underline{\delta}$ in the case of transferring the risk in a junior position, where $\underline{\delta}=\delta-\frac{1-\omega}{\omega}(\bar{y}-\delta)$.

Proof. See Appendix.

The proposition replaces the $\delta$ in Proposition 1 by $\underline{\delta}$, which is a decreasing function of $\bar{y}-\delta$. The magnitude of $\bar{y}-\delta$ reflects the upward potential of the return on investment $Y$ relative to the overall insolvency threshold. If the maximum realization of $y$ is too large, then there will exist some contingencies in which the credit risk transfer will be beneficial in 
terms of insolvency risk, which implies that the increase in insolvency risk is not guaranteed for every $\phi(x, y)$.

In summary, a higher degree of diversification limits the number of cases in which it will be possible to discern whether a credit risk transfer increases or reduces a bank's insolvency risk without making assumptions on $\phi(x, y)$. In the context of bank loan portfolios, diversification will be more restrictive regarding conclusions on a reduction in insolvency risk than on an increase in insolvency risk, because the magnitude of $\bar{y}-\delta$ in Proposition $2 \mathrm{~b}$ can be considered small relative to $\delta-\underline{y}$ in Proposition 2a. The reason is that in the context of loan portfolios, $\bar{y}$ will be close to one since it is directly linked to the gross return charged to borrowers, while $\delta$ will be close to one due to bank leverage. By contrast, $\underline{y}$ will generally be far from one because it depends on the loss in the worst case scenario.

\subsection{Illustration}

Before continuing to the analysis with endogenous funding costs, it will be useful to provide an illustration on the results so far (parameter values have been chosen such that it doesn't matter for the conclusions whether we consider exogenous or endogenous funding costs).

Consider a hypothetical bank specialized in mortgage loans for house purchases and auto loans. The balance sheet of the bank is provided in Figure 2. The bank charges its clients, on average, an interest rate of 4 per cent on mortgage loans, and an interest rate of 13 per cent on auto loans. In the worst case scenario, the portfolio of auto loans will return 45 cents on the dollar. Moreover, depositors earn on average an interest rate of 1 per cent on their balances. Based on this information, we have the parameter values $\omega=0.9, d=0.95$, $\bar{x}=1.04, \underline{y}=0.45, \bar{y}=1.13, \delta=0.9595$, and $\omega=0.9$.

The bank considers transferring the risk for the pool of mortgage loans to reduce the risk on the balance sheet through securitization. Figure 2 also shows the potential structure of the securitized loan pool, with the threshold between the senior and the junior tranche set at 90 cents on the dollar. Market analysis suggests that for each dollar of mortgages in the pool, the securitized senior position could be sold to third-party investors for 88 cents, while 
Figure 2: Hypothetical bank balance sheet and a securitization transaction

\begin{tabular}{|l|c|l|c|}
\hline \multicolumn{3}{|c|}{ Hypothetical Balance Sheet } \\
\hline \multicolumn{2}{|c|}{ Assets } & \multicolumn{2}{c|}{ Liabilities } \\
\hline Mortgages & 90 & Deposits & 95 \\
\hline Auto Loans & 10 & Equity Capital & 5 \\
\hline
\end{tabular}

Interest rate charged on mortgages: $4 \%$

Interest rate charged on auto loans: $13 \%$

(worst case scenario: 45 cents on the dollar)

Interest rate earned by depositors: $1 \%$

\section{Structure of Transaction}

Per dollar of mortgage loans:

Price:

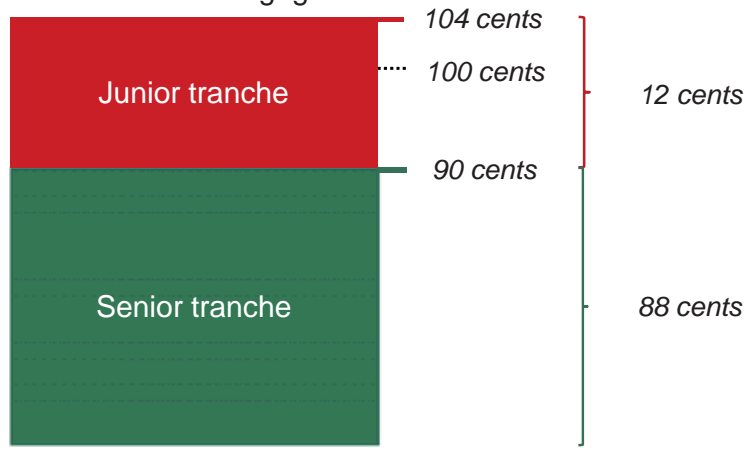

Note: This securitization transaction illustrates the results in Propositions $2 \mathrm{a}-3 \mathrm{~b}$. The direct impact of selling a proportion of the senior tranche is an increase in the insolvency risk of the bank, while the direct impact of selling a proportion of the equity tranche is a reduction in insolvency risk. Parameter values have been chosen such that it doesn't matter whether the interest rate earned by depositors is fixed (Propositions $2 \mathrm{a}$ and $2 \mathrm{~b}$ ), or whether it changes in response to the credit risk transfer as implied by Eq. (7) (Propositions $3 \mathrm{a}$ and $3 \mathrm{~b})$.

the first-loss position could be sold for 12 cents (respectively, an effective interest rate of approximately 2.3 per cent and 16.7 per cent). This information gives the parameter values $k=0.9, p(0.9)=0.88$ and $q(0.9)=0.12$.

Is selling a proportion of the tranches in the securitization beneficial for the bank from an insolvency risk point of view? From Proposition $2 \mathrm{a}$, we have $\bar{\delta} \approx 1.016$, which is smaller than $k+q(k)=1.02$, and hence, selling the first-loss position while retaining the senior position will certainly reduce the bank's insolvency probability. On the other hand, from Proposition $2 \mathrm{~b}$, we have $\underline{\delta} \approx 0.941$, which is larger than $p(k)=0.88$, and therefore, selling the senior position while retaining the first-loss position will certainly increase the bank's insolvency probability. Interestingly, the first transaction, which increases insolvency risk, is in general not compliant with risk retention regulation that has been introduced in several jurisdictions, while the second transaction, which increases insolvency risk, generally is. We will return to this issue at a later point in the paper. 
Is the impact of the transactions large or small in terms of magnitude? Obviously, it is not possible to express the magnitude of the impact in terms of probabilities without further assumptions on the probability distribution functions. However, in some cases, it is possible to express the effect in terms of an effective capital impact. This is in particular possible for transfers of the credit risk in senior positions that increase insolvency risk, for transfers of the credit risk in junior positions that reduce insolvency risk, and for all full risk transfers. ${ }^{6}$

Let the unweighted capital ratio ('leverage ratio') before the transaction be denoted as $l=1-d$. Moreover, let $l_{i}^{A}$ denote the effective level of this leverage ratio after the transaction, which is interpreted as the level at which the leverage ratio of the old bank would have been operating if it had the same insolvency probability as the bank after the transaction. Note that $l_{i}^{A}-l$ equals the effective capital impact of the transaction on the insolvency probability, but does not necessarily correspond to the change in the actual leverage ratio of the bank. Conditional upon a risk transfer of the junior position increasing the bank's insolvency probability, the level of $l_{j}^{A}$ equals

$$
l_{j}^{A}=l+\omega r q(k) \times d / \delta .
$$

Moreover, conditional upon a risk transfer of the senior position increasing the bank's insolvency probability, the level of $l_{s}^{A}$ equals

$$
l_{s}^{A}=l-\omega r(k-p(k)) \times d / \delta .
$$

When returning to the numerical example, Eq. (5) implies that a full-scale transaction (i.e., $r=1$ ) to transfer the risk in the junior position would have an impact on the insolvency probability that is equivalent to an increase in the leverage ratio of 10.7 percentage points. Similarly, a full-scale transaction to transfer the risk in the senior position would have an impact on the insolvency probability that is equivalent to a reduction in the leverage ratio

\footnotetext{
${ }^{6}$ The reason is that those transactions effectively result in a vertical shift in the level of $x_{i, k}(y, r)$ for all $y \in[\underline{y}, \bar{y}]$, which can subsequently be translated in a change in leverage while assuming a fixed funding cost.
} 
of 1.8 percentage points. In other words, after the risk transfer in the senior position, the bank's insolvency probability would equal that of the bank prior to the transaction if it were operating with an unweighted capital ratio of 3.2 per cent instead of 5.0 per cent. Hence, from a regulatory perspective, the direct impact of these transactions can be considerable.

\subsection{Endogenous Funding Costs}

So far, the analysis relies on assuming that the bank's funding cost does not respond to the credit risk transfer. Note, however, that the potentially harmful direct impact of credit risk transfer on the probability of failure could be attenuated by a reduction in the rate of interest on bank deposits in response to credit risk transfer. In this section, we discuss the results under the assumption that the rate of interest on bank deposits is endogenous.

Endogenous funding costs are modelled as follows. Without accounting for additional insolvency costs, the principal and interest that the bank owes to its depositors at the end of the period, $\delta_{i, k}(r)$, is implicitly defined as

$$
d=\int_{0}^{\infty} \int_{0}^{\infty} \phi^{Q}(x, y) \min \left\{v_{i, k}(x, y, r), \delta_{i, k}(r)\right\} \mathrm{d} x \mathrm{~d} y
$$

where $\phi^{Q}(x, y)$ reflects the risk-neutral probability density function of the depositors. The form in Eq. (7) is flexible to allow for subjectivity in perceived probabilities in terms of divergence in opinions à la Chan and Kanatas (1985) or various types of risk preferences, since it is not assumed that $\phi^{Q}(x, y)$ reflects the true $\phi(x, y)$. Moreover, for the purpose of the discussion, it will also be convenient to define the subjective, or risk-neutral, insolvency probability from the perspective of the bank's depositors as

$$
\pi_{i, k}^{Q}(r)=\int_{0}^{\infty} \int_{0}^{x_{i, k}^{*}(y, r)} \phi^{Q}(x, y) \mathrm{d} x \mathrm{~d} y
$$

The general line of the proof of the propositions with endogenous bank funding costs is as follows. The credit risk transfer strategy must increase or decrease the bank's insolvency 
probability in (3) for any continuous probability density function $\phi(x, y)$ with full support $[0, \bar{x}] \times[\underline{y}, \bar{y}]$, if the derivative

$$
\frac{\partial x_{i, k}^{*}(y, r)}{\partial r} \lessgtr 0
$$

for every $(y, r) \in[\underline{y}, \bar{y}] \times[0, r]$. A difficult factor in showing under which conditions this holds true is that the derivative in (9) is also a function of $\partial \delta_{i, k}(r) / \partial r$, which is typically nonzero if the bank's funding cost responds to changes in the risk of the investments held by the bank. The proof relies on deriving the level of $\partial \delta_{i, k}(r) / \partial r$ from Eq. (7) with implicit derivation.

In the case of deriving the condition for the credit risk transfer for the senior tranche, it will be necessary to also assume that the risk premium required by depositors when putting money in a hypothetical bank investing solely in the senior position is at least smaller or equal to the risk premium required by third-party investors or the insurer, i.e.,

$$
k-p(k) \geq k-p^{Q}(k)=k-\int_{0}^{\infty} \int_{0}^{\infty} \phi^{Q}(x, y) \min \{x, k\} \mathrm{d} x \mathrm{~d} y .
$$

Note that this condition is even satisfied if depositors, in spite of deposit insurance, fully appreciate the reduction in the risk of the bank's cash flow in lowering the interest rate that they require, and if credit risk transfer is fairly priced (i.e., providers of credit risk protection price risk using the same $\left.\phi^{Q}(x, y)\right){ }^{7}$

The reason why the proof requires an assumption such as the one in (10) is straightforward. After transferring the credit risk in the senior position, the bank bears the cost of credit risk protection. With endogenous funding costs, the interest expenses of the bank may drop in response to the credit risk transfer. The condition in (10) ensures that the interest expenses of the bank do not drop more than is justified by the reduction in asset risk, although they are allowed to drop with less.

With these preparations, the following proposition shows that the conditions under which the credit risk transfer increases the insolvency probability do not change much.

\footnotetext{
${ }^{7}$ Explicit or implicit guarantees on bank debt, such as deposit insurance, reduce the level of $k-p^{Q}(k)$. On the other hand, subsidies on securitization or credit portfolio insurance programs could impact the level of the risk premium $k-p(k)$.
} 
Proposition 3a The credit risk transfer strictly increases the insolvency probability of a bank with endogenous funding costs if

1. $k<\underline{\delta}$ in the case of transferring the risk in a senior position and the assumption in (10) holds true;

2. $p(k)+q(k)+(\delta-d)<\underline{\delta}$ in the case of a full risk transfer;

3. $k+q(k)+(\delta-d)<\underline{\delta}$ in the case of transferring the risk in a junior position,

where $\underline{\delta}=\delta-\frac{1-\omega}{\omega}(\bar{y}-\delta)$.

Proof. See Appendix.

With endogenous funding costs, the conditions for the full risk transfer and the transfer of the risk in the junior position also include an adjustment for the risk premium required by depositors in the absence of credit risk transfer, i.e., $\delta-d$. The magnitude of this component can be illustrated with an example: A specialized bank that is financed with 10 per cent equity and a risk premium required by depositors of 2 per cent corresponds to parameter values of $\underline{\delta}=0.918$ and $\delta-d=0.018$. This implies that with exogenous funding costs, a full credit risk transfer increases the insolvency probability if the bank receives less than 91.8 cents on the dollar, while with endogenous funding costs, the threshold is reduced to 90 cents on the dollar. In other words, the relevant threshold depends not only on the amount of debt, but also on the risk premium promised to depositors.

Moreover, with endogenous funding costs, transferring the risk in the senior position can still increase the insolvency risk of the bank. The underlying reason is that the interest expense will not drop by the full amount of the cost of the insurance, even if the credit risk transfer is fairly priced (i.e., using the same $\phi^{Q}(x, y)$ ), and if depositors, in spite of deposit insurance, fully appreciate the reduction in the risk of the bank's cash flow in lowering interest required on bank deposits. The reason is that the depositors still end up paying for the cost of credit risk protection if the bank fails, which occurs with a perceived probability of $\pi_{s, k}^{Q}(r)$. Therefore, the funding cost of the bank does not drop by as much as the cost of 
the credit risk protection, resulting, overall, in a higher threshold return necessary to avoid bank failures.

Similarly, the conditions under which credit risk transfer reduces the insolvency probability do not change much, as is shown in the following proposition.

Proposition $3 \mathrm{~b}$ The credit risk transfer strictly reduces the insolvency probability of a bank with endogenous funding costs if

1. $p(k)>\bar{\delta}$ in the case of transferring the risk in a senior position;

2. $p(k)+q(k)+(\delta-d)>\bar{\delta}$ in the case of a full risk transfer;

3. $k+q(k)>\bar{\delta}$ in the case of transferring the risk in a junior position, where $\bar{\delta}=\delta+\frac{1-\omega}{\omega}(\delta-\underline{y})$.

Finally, it may be useful to stress that the statements on the reductions and increases in the bank's insolvency probabilities in the propositions apply to both the actual and the perceived failure probabilities, i.e., $\pi_{i, k}(r)$ and $\pi_{i, k}^{Q}(r)$. The reason is that the propositions do not rely on the precise functional form of $\phi(x, y)$. This implies that the direction of the impact will be correct, even if the perceived insolvency probability is far from accurate.

\section{Discussion}

\subsection{Unbounded Distribution}

The results in the analysis are defined in terms of bounds on the returns on the bank's other assets $Y$. Although bounds can be relatively straightforward to obtain in the context of loan portfolios, this can be restrictive if the investments in stocks or foreign currencies, which, at least in principle, could offer an infinitely high return. In such a case, a risk manager can still determine whether a credit risk transfer reduces the bank's insolvency risk with a minimum level of confidence, even when only limited information on the probability distribution of $y$ is available. 
Let $Q_{y}(\alpha)$ define the quantile of $y$ defined as $Q_{y}(\alpha)=\sup \{c: \operatorname{Pr}(y \leq c) \leq \alpha\}$. Then it follows that the credit risk transfer reduces the bank's insolvency risk with at least a confidence level $(1-\alpha)$ if the conditions in Lemma 1 hold true for $x_{i, k}^{*}=x_{i, k}^{*}\left(Q_{y}(\alpha), 0\right)$. Suppose that the risk manager has no knowledge of the statistical distribution of $y$, except for the levels of the finite mean $\mu_{y}$ and variance $\sigma_{y}^{2}$. Without any further information regarding the statistical distribution, one can use, for example, Tchebycheff's inequality to obtain $Q_{y}(\alpha) \geq \mu_{y}-\sigma_{y} / \sqrt{\alpha}$ (see, e.g., Telser (1955) for an application of this inequality in a safety-first environment). As a consequence, a credit risk transfer must reduce the bank's insolvency risk with a confidence level of at least $(1-\alpha)$ if the conditions in Lemma 1 hold true for

$$
x_{i, k}^{*}=\delta+\frac{1-\omega}{\omega}\left(\delta+\frac{\sigma_{y}}{\sqrt{\alpha}}-\mu_{y}\right) .
$$

Of course, a tighter condition resulting in a lower $x_{i, k}^{*}$ can be obtained if the risk manager has access to more properties of the statistical distribution of $y .{ }^{8}$ The level of the quantile $Q_{y}(\alpha)$ minus one is a central risk measure in financial risk management and is often referred to as the 'Value-at-Risk' of a portfolio, which has the interpretation of the maximum loss that is not exceeded with a confidence level $(1-\alpha)$. Estimating the level of this risk measure using historical data and different modelling approaches is the subject of extant literature.

Applying the condition in Eq. (11) may also be useful to obtain a sharper condition in situations where the distribution of $Y$ is bounded, but where the downside risk defined as $\delta-\underline{y}$ is large. In this case, the cost associated with a condition for absolute certainty about the reduction in insolvency risk in a 'distribution-free' setting could be relatively high.

\footnotetext{
${ }^{8}$ In some specific cases, it is also possible to obtain a tighter condition if the risk manager has more information on the joint distribution of $(x, y)$, without additional information on the marginal distribution of $y$. For example, consider the case where a risk manager wants to approve a transfer of credit risk in a junior position only if that transaction, with a confidence level $1-\alpha$, either reduces insolvency risk or results in an ex-post net benefit of the transaction. Suppose that the risk manager observes the finite first and second moments of the distribution $\phi(x, y)$. In this specific case, if the correlation coefficient $\left\|\rho_{x, y}\right\|<1 / \sqrt{2}$, then a tighter bound can be obtained for a sufficiently large $k+q(k)>\mu_{x}$ and a sufficiently small $\alpha$. From the multivariate form of Tchebysheff's inequality formulated by Lal (1955, Eq. B), it follows that the $x_{i, k}^{*}$ in Eq. (11) could be replaced by $x_{i, k}^{*}=\delta+\frac{1-\omega}{\omega}\left(\delta+Z \times \sigma_{y} / \sqrt{\alpha}-\mu_{y}\right)$, where $Z=\sqrt{\left(2 \rho^{2}-\alpha z_{x}^{2}\right) /\left(1-\alpha z_{x}^{2}\right)}$ and $z_{x}=\left(k+q(k)-\mu_{x}\right) / \sigma_{x}$.
} 
The condition in Eq. (11) may then provide a sharper condition at a reasonable level of confidence $\alpha$, especially when the variation based on $\sigma_{y}$ is relatively small.

\subsection{Adverse Selection}

Adverse selection in the context of credit risk transfer generally refers to the case where the lender uses private information to select lower quality loans into the asset pool involved in the credit risk transfer. Our framework is sufficiently broad to allow for adverse selection. Asset $X$ may represent the pool with a selection of low-quality borrowers, while $Y$ represents the pool of loans to high-quality borrowers. Of course, insurance providers may require a higher premium, or third-party investors may require a higher yield on tranches in securitizations, if they anticipate adverse selection. Hence, adverse selection may potentially reduce the level of $p(k)$ and $q(k)$. From our propositions, such a discount makes it more likely that the conditions for which credit risk transfers increase the insolvency probability are binding. Therefore, anticipation of adverse selection can be a factor that contributes to an increase in bank insolvency risk as a consequence of a credit risk transfer.

\subsection{Moral Hazard}

With moral hazard, the end-of-period cash flow from the asset pool (after deducting the operating cost) may depend on the structure of the credit risk transfer. For example, after transferring the risk in the senior position, the originator could save on the operating cost of the asset pool by a reduction in monitoring. Theoretically, such an action may result in higher losses in states corresponding to adverse tail events and lower costs in the other states

of the world; see, e.g., Chiesa (2008). Dependence between the return distribution (net of the operating cost) and the structure of the credit risk transfer is a violation of the assumptions in the model. The essential difference with adverse selection is that once asset pool $X$ is constructed, the return distribution is not affected by the credit risk transfer strategy. With moral hazard, the return distribution (net of the operating cost) does change depending on the structure of the credit risk transfer. Therefore, the propositions do not generally hold 
true with moral hazard. However, in the special case that moral hazard results in a cost saving by the bank without affecting the risk distribution of the retained interest, then the propositions can still be applied by simply adding the bank's cost saving to the purchase price paid by the third-party investors.

\section{Concluding Remarks}

After the financial crisis, authorities in several jurisdictions implemented forms of mandatory credit risk retention for banks engaging in credit risk transfer. For example, credit risk retention regulation has been implemented in the EU (Regulation No 575/2013, Article 405) and the US (CFR Title 17, Chapter II, Part 246). ${ }^{9}$ Inspired by the literature on information asymmetries in credit risk transfers, regulators have had a main objective for mandatory risk retention: to better align the incentives of banks and investors.

Regulation of credit risk retention usually requires exposure to a certain fraction of the unhedged credit risk after the credit risk transfer, where the institution has the choice of different forms of credit risk retention. Broadly speaking, under current regulation, the choice boils down to either retaining an exposure of not less than 5 per cent to the credit risk in all positions ('vertical' interest), or retaining an exposure to a first-loss position of not less than 5 per cent ('horizontal residual' interest). ${ }^{10}$ Moreover, in some jurisdictions, including the US, a combination of vertical and horizontal residual interests is also allowed.

Although aligning incentives between banks and investors is important, credit risk retention regulation in its current form may advocate transactions whose direct impact is to increase bank insolvency risk. For example, in the illustration discussed in Subsection 4.2, transferring the credit risk in the first-loss position while retaining the risk in the senior position would reduce bank insolvency risk, but this transaction would typically not comply with the aforementioned credit risk retention regulation. In contrast, the transaction in which the

\footnotetext{
${ }^{9}$ In 2014, the Canadian Securities Administrators (CSA) decided not to propose the introduction of mandatory credit risk retention in Canada.

${ }^{10}$ For a precise description of the options, we refer to the regulatory texts.
} 
bank transfers the risk in the senior position and retains the risk in the first-loss position does comply with credit risk retention regulation, but the direct impact of this transaction is to increase bank insolvency risk.

Whether a transaction in which the bank retains the first-loss position increases insolvency risk depends on how the retained position compares with the unweighted capital ratio of the bank. To see this, let the size of the economic interest in the form of a retained firstloss position be denoted as $f=1-p(k)$. Moreoever, let $f^{*}$ denote the mandatory minimum retained interest if the bank retains a first-loss position, such that $f \geq f^{*}$. Then using this notation in, for example, the condition in Proposition 1 we find that any credit risk transfer of the senior position complying with the regulation will increase insolvency risk of the bank if

$$
f^{*}>l-(\delta-d) .
$$

With $\delta-d \geq 0$, we have that the condition in (12) is a binding constraint if $f^{*}>l$, which depends on the level of the unweighted capital ratio of a bank.

Figure 3 illustrates this condition by reporting the level of tangible common equity as a ratio of total assets for the 50 largest commercial banks around the globe. About a third of these banks operate with an unweighted capital ratio smaller than 5 per cent, which suggests that the condition in (12), with a current $f^{*}=0.05$, is far from hypothetical in the current banking landscape. Moreover, some have suggested to increase the level of $f^{*}$ going forward, which corresponds to an upward shift of the horizontal dashed line in Figure 3. For example, lawmakers in the EU have proposed that the European Banking Authority should review the level of the risk retention rate between 5 per cent and 20 per cent every two years; see the report of the Committee on Economic and Monetary Affairs (2016).

Without an increase in the levels of banks' capital ratios, risk retention requirements may move banks further into the quadrant of retaining substantial first-loss positions and relatively thin capital buffers. The present analysis shows that such a combination could turn out to be a toxic cocktail in times of financial headwinds. Of course, increasing banks' capital ratios may be one way to address this issue, but another - and perhaps more feasible 
Figure 3: Commercial banks' tangible common equity, as a percentage of total assets

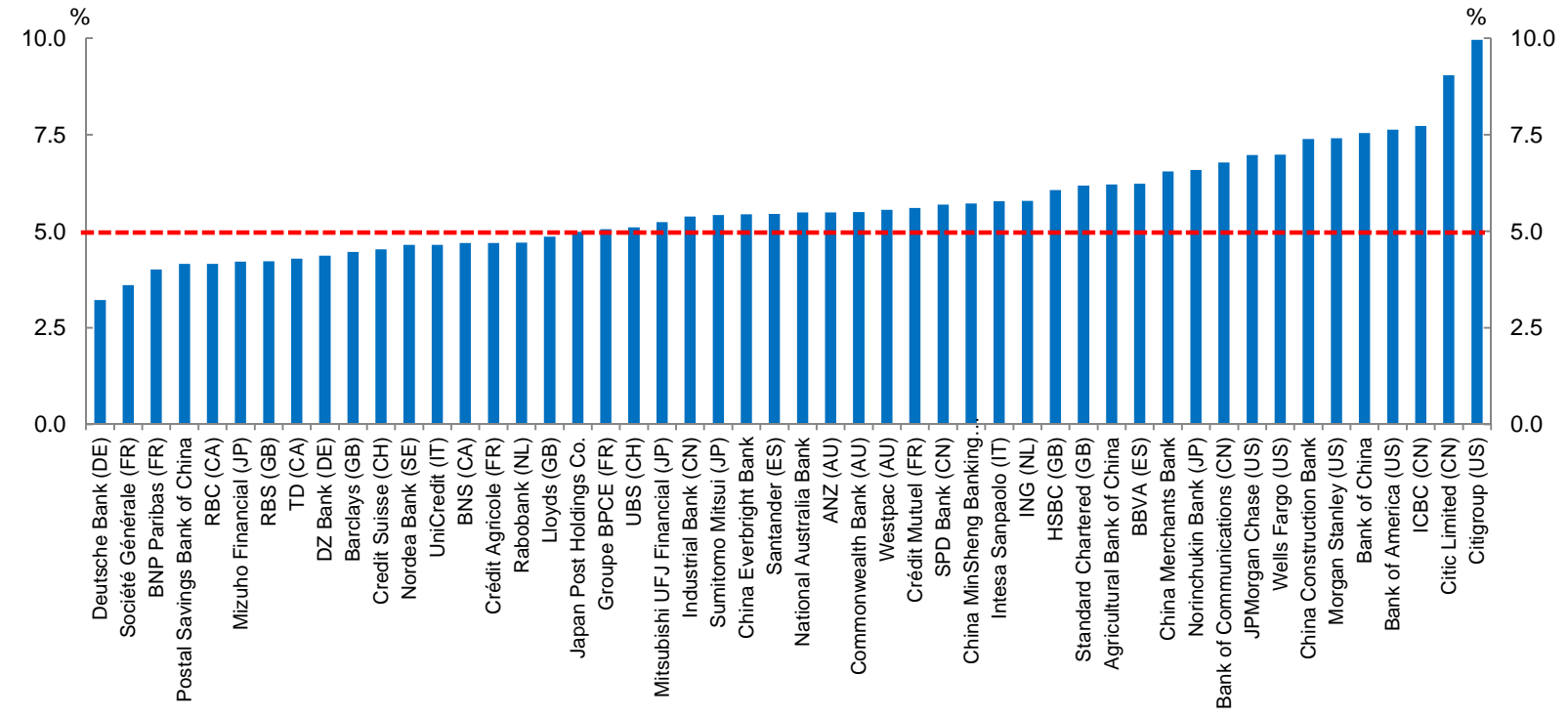

Note: The figure illustrates the condition in Eq. (12) for the 50 largest commercial banks by total assets. The red dashed line corresponds to the minimum mandatory retained interest of 5 per cent, i.e., $f^{*}$. The blue bars correspond to the unweighted capital ratios, i.e., $l$. With $\delta-d \geq 0$, the condition in (12) is binding for more than a third of the banks. Source: Fitch Connect. The numbers refer to end of fiscal 2016 for most banks.

- solution is to limit the option of complying with risk retention regulation through the retention of first-loss positions for those banks with low unweighted capital ratios. 


\section{Appendix: Proofs}

\section{A.1 Proposition 1}

Proposition 1 follows from Propositions $2 \mathrm{a}$ and $2 \mathrm{~b}$ with $\omega=1$.

\section{A.2 Propositions $2 \mathrm{a}$ and $2 \mathrm{~b}$}

From (2), we have

$$
\begin{aligned}
\pi_{i, k}(0) & =\operatorname{Pr}[\omega x<\delta-(1-\omega) y] \\
& =\operatorname{Pr}[\omega x<\delta-(1-\omega) y, x \leq k]+\operatorname{Pr}[\omega x<\delta-(1-\omega) y, x>k] \\
& :=A_{0}+B_{0} .
\end{aligned}
$$

\section{A.2.1 Transfer risk in the senior position}

From (1) and (2), we have for $i=s$

$$
\begin{aligned}
\pi_{s, k}(r)= & \operatorname{Pr}[\omega(x+r p(k)-r \min \{x, k\})<\delta-(1-\omega) y] \\
= & \operatorname{Pr}\left[\omega x<\delta-(1-\omega) y+\frac{r}{1-r}(\delta-(1-\omega) y-\omega p(k)), x \leq k\right] \\
& +\operatorname{Pr}[\omega x<\delta-(1-\omega) y+\omega r(k-p(k)), x>k] ; \\
:= & A_{s}+B_{s} .
\end{aligned}
$$

From a comparison of (14) and (17) it follows that $A_{s}>A_{0}$ if $\delta-(1-\omega) y-\omega p(k)>0 \forall y \in$ $[\underline{y}, \bar{y}]$, i.e., if $p(k)<\delta-\frac{1-\omega}{\omega}(y-\delta) \forall y \in[\underline{y}, \bar{y}]$, which is implied by $p(k)<\delta-\frac{1-\omega}{\omega}(\bar{y}-\delta)$. Further, from a comparison of (14) and (17) it follows that $B_{s} \geq B_{0}$, since $k-p(k)>0$. Hence, $p(k)<\delta-\frac{1-\omega}{\omega}(\bar{y}-\delta)$ implies $A_{s}+B_{s}>A_{0}+B_{0}$, or, $\pi_{s, k}(r)>\pi_{i, k}(0) \forall r \in(0,1]$.

From a comparison of (14) and (17) it follows that $A_{s}<A_{0}$ if $\delta-(1-\omega) y-\omega p(k)<$ $0 \forall y \in[\underline{y}, \bar{y}]$, i.e., if $p(k)>\delta+\frac{1-\omega}{\omega}(\delta-y) \forall y \in[\underline{y}, \bar{y}]$, which is implied by $p(k)>\delta+\frac{1-\omega}{\omega}(\delta-\underline{y})$. 
Further, from (17), with this condition we have

$$
\begin{aligned}
B_{s} & =\operatorname{Pr}[\omega k<\omega x<\delta-(1-\omega) y+\omega r(k-p(k))] \\
& \leq \operatorname{Pr}\left[\omega k<\omega x<\delta-(1-\omega) \underline{y}+\omega r\left(k-\delta-\frac{1-\omega}{\omega}(\delta-\underline{y})\right)\right] \\
& =\operatorname{Pr}\left[k<\frac{x-r k}{1-r}<\delta+\frac{1-\omega}{\omega}(\delta-\underline{y})\right] .
\end{aligned}
$$

Since $k>p(k)$, with this condition we also have $k>\delta+\frac{1-\omega}{\omega}(\delta-\underline{y})$. Using this inequality in (17) gives

$$
\begin{aligned}
B_{s} & \leq \operatorname{Pr}\left[\delta+\frac{1-\omega}{\omega}(\delta-\underline{y})<\frac{x-r k}{1-r}<\delta+\frac{1-\omega}{\omega}(\delta-\underline{y})\right] \\
& =0 .
\end{aligned}
$$

Following a similar argument, $B_{0}=0$ if $k>\delta+\frac{1-\omega}{\omega}(\delta-\underline{y})$. Hence, $p(k)>\delta+\frac{1-\omega}{\omega}(\delta-\underline{y})$ implies $A_{s}<A_{0}$ and $B_{s}=B_{0}=0$, or, $\pi_{s, k}(r)<\pi_{i, k}(0) \forall r \in(0,1]$.

\section{A.2.2 Full risk transfer}

From (1) and (2) follows the insolvency probability for $i=f$ as

$$
\pi_{f, k}(r)=\operatorname{Pr}\left[\omega x<\delta-(1-\omega) y+\frac{r}{1-r}(\delta-(1-\omega) y-\omega(p(k)+q(k)))\right] .
$$

From a comparison of (13) and (20) it follows that $\pi_{f, k}(r)<\pi_{i, k}(0) \forall r \in(0,1]$ if $\delta-(1-$ $\omega) y-\omega(p(k)+q(k))<0 \forall y \in[\underline{y}, \bar{y}]$, i.e., if $p(k)+q(k)<\delta+\frac{1-\omega}{\omega}(\delta-y) \forall y \in[\underline{y}, \bar{y}]$, which is implied by $p(k)+q(k)>\delta+\frac{1-\omega}{\omega}(\delta-\underline{y})$.

From a comparison of (13) and (20) it follows that $\pi_{f, k}(r)>\pi_{i, k}(0) \forall r \in(0,1]$ if $\delta-(1-$ $\omega) y-\omega(p(k)+q(k))>0 \forall y \in[\underline{y}, \bar{y}]$, i.e., if $p(k)+q(k)<\delta-\frac{1-\omega}{\omega}(y-\delta) \forall y \in[\underline{y}, \bar{y}]$, which is implied by $p(k)+q(k)<\delta-\frac{1-\omega}{\omega}(\bar{y}-\delta)$. 


\section{A.2.3 Transfer risk in the junior position}

From (1) and (2) follows the insolvency probability for $i=j$ as

$$
\begin{aligned}
\pi_{j, k}(r)= & \operatorname{Pr}[\omega(x-r \max \{x-k, 0\}+r q(k))<\delta-(1-\omega) y] \\
= & \operatorname{Pr}[\omega(x+r q(k))<\delta-(1-\omega) y, x \leq k] \\
& +\operatorname{Pr}\left[\omega x<\delta-(1-\omega) y+\frac{r}{1-r}(\delta-(1-\omega) y-\omega(k+q(k))), x>k\right] \\
:= & A_{j}+B_{j} .
\end{aligned}
$$

From a comparison of (14) and (22) it follows that $A_{j} \leq A_{0}$, since $x \leq x+r q(k)$. Further, from a comparison of (14) and (22) it follows that $B_{j}<B_{0}$ if $\delta-(1-\omega) y-\omega(k+q(k))<0 \forall y \in$ $[\underline{y}, \bar{y}]$, i.e., if $k+q(k)>\delta+\frac{1-\omega}{\omega}(\delta-y) \forall y \in[\underline{y}, \bar{y}]$, which is implied by $k+q(k)>\delta+\frac{1-\omega}{\omega}(\delta-\underline{y})$. Hence, this condition implies $A_{j}+B_{j}<A_{0}+B_{0}$, or, $\pi_{j, k}(r)<\pi_{i, k}(0) \forall r \in(0,1]$.

Since $x \leq x+r q(k)$, it follows from a comparison of (14) and (22) that $A_{j}=A_{0}$ if $\omega(x+r q(k))<\delta-(1-\omega) y \forall(x, y) \in[0, k] \times[\underline{y}, \bar{y}]$, which is implied by $\omega(k+r q(k))<$ $\delta-(1-\omega) \bar{y}$, i.e., $k+r q(k)<\delta+\frac{1-\omega}{\omega}(\delta-\bar{y})$. Further, from a comparison of (14) and (22) it follows that $B_{j}>B_{0}$ if $\delta-(1-\omega) y-\omega(k+q(k))>0 \forall y \in[\underline{y}, \bar{y}]$, i.e., if $k+q(k)<$ $\delta-\frac{1-\omega}{\omega}(y-\delta) \forall y \in[\underline{y}, \bar{y}]$, which is implied by $k+q(k)<\delta-\frac{1-\omega}{\omega}(\bar{y}-\delta)$. This condition for $B_{j}>B_{0}$ implies the (weaker) condition for $A_{j}=A_{0}$, since $k+r q(k)<k+q(k)$. Hence, $k+q(k)<\delta-\frac{1-\omega}{\omega}(\bar{y}-\delta)$ implies $A_{j}+B_{j}>A_{0}+B_{0}$, or, $\pi_{j, k}(r)>\pi_{i, k}(0) \forall r \in(0,1]$.

\section{A.3 Propositions $3 \mathrm{a}$ and $3 \mathrm{~b}$}

\section{A.3.1 Full risk transfer}

For the strategy with the full risk transfer, we have

$$
x_{f, k}^{*}(y, r)=\frac{\delta_{f, k}(r)-(1-\omega) y-r \omega(p(k)+q(k))}{(1-r) \omega} .
$$


From this follows

$$
\frac{\partial x_{f, k}^{*}(y, r)}{\partial r}=\frac{(1-r) \frac{\partial \delta_{f, k}(r)}{\partial r}+\delta_{f, k}(r)-(1-\omega) y-\omega(p(k)+q(k))}{(1-r)^{2} \omega} .
$$

To obtain $\partial \delta_{f, k}(r) / \partial r$, we write (7) for the full risk transfer as

$$
\begin{aligned}
d= & \int_{0}^{\infty} \int_{x_{f, k}^{*}(y, r)}^{\infty} \phi^{Q}(x, y) \delta_{i, k}(r) \mathrm{d} x \mathrm{~d} y+ \\
& \int_{0}^{\infty} \int_{0}^{x_{f, k}^{*}(y, r)} \phi^{Q}(x, y)(\omega[x+r(p(k)+q(k))]+(1-\omega) y) \mathrm{d} x \mathrm{~d} y .
\end{aligned}
$$

Taking the implicit derivative of (26) to $r$ gives

$$
\begin{aligned}
0= & \int_{0}^{\infty} \int_{x_{f, k}^{*}(y, r)}^{\infty} \phi^{Q}(x, y) \frac{\partial \delta_{f, k}(r)}{\partial r} \mathrm{~d} x \mathrm{~d} y+ \\
& \omega \int_{0}^{\infty} \int_{0}^{x_{f, k}^{*}(y, r)} \phi^{Q}(x, y)[(p(k)+q(k))-x] \mathrm{d} x \mathrm{~d} y,
\end{aligned}
$$

where we use the fact that $v_{f, k}\left(x_{f, k}^{*}(y, r), y, r\right)=\delta_{i, k}(r)$. Rewriting Eq. (27) using the notation for $\pi_{i, k}^{Q}(r)$ in (8) gives

$$
\frac{\partial \delta_{f, k}(r)}{\partial r}=-\frac{\omega \pi_{f, k}^{Q}(r)\left(p(k)+q(k)-\delta_{f, k}(r)\right)+\omega \int_{0}^{\infty} \int_{0}^{x_{f, k}^{*}(y, r)} \phi^{Q}(x, y)\left(\delta_{f, k}(r)-x\right) \mathrm{d} x \mathrm{~d} y}{1-\pi_{f, k}^{Q}(r)}
$$

Moreover, rewriting (26) gives

$$
\begin{aligned}
\left(\delta_{f, k}(r)-d\right)= & \omega(1-r) \int_{0}^{\infty} \int_{0}^{x_{f, k}^{*}(y, r)} \phi^{Q}(x, y)\left(\delta_{f, k}(r)-x\right) \mathrm{d} x \mathrm{~d} y \\
& +\omega r \int_{0}^{\infty} \int_{0}^{x_{f, k}^{*}(y, r)} \phi^{Q}(x, y)\left(\delta_{f, k}(r)-(p(k)+q(k))\right) \mathrm{d} x \mathrm{~d} y \\
& +(1-\omega) \int_{0}^{\infty} \int_{0}^{x_{f, k}^{*}(y, r)} \phi^{Q}(x, y)\left(\delta_{f, k}(r)-y\right) \mathrm{d} x \mathrm{~d} y .
\end{aligned}
$$


Using (29) to rewrite Eq. (27) gives

$$
\frac{\partial \delta_{f, k}(r)}{\partial r}=-\frac{\left(\delta_{f, k}(r)-d\right)-\int_{0}^{\infty} \int_{0}^{x_{f, k}^{*}(y, r)} \phi^{Q}(x, y)\left[\delta_{f, k}(r)-\omega(p(k)+q(k))-(1-\omega) y\right] \mathrm{d} x \mathrm{~d} y}{\left(1-\pi_{f, k}^{Q}(r)\right)(1-r)} .
$$

Combining the specification of $\partial \delta_{f, k}(r) / \partial r$ in (30) and that of $x_{f, k}^{*}(y, r)$ in (25), while using

the definition of $\pi_{i, k}^{Q}(r)$ in (8), gives the final equation for the derivative of the threshold return with respect to changes in the fraction of asset $X$ involved in the credit risk transfer

$$
\begin{aligned}
\frac{\partial x_{f, k}^{*}(y, r)}{\partial r}= & {\left[\left(1-\pi_{f, k}^{Q}(r)\right)(d-\omega(p(k)+q(k))-(1-\omega) y)\right.} \\
& \left.+\int_{0}^{\infty} \int_{0}^{x_{f, k}^{*}(y, r)} \phi^{Q}(x, y)(d-\omega(p(k)+q(k))-(1-\omega) y) \mathrm{d} x \mathrm{~d} y\right] / \\
& {\left[(1-r)^{2} \omega\left(1-\pi_{f, k}^{Q}(r)\right)\right] . }
\end{aligned}
$$

The denominator of Eq. (31) is positive for any $r \in[0,1]$. Moreover, the numerator will be positive if $p(k)+q(k)>d+\frac{1-\omega}{\omega}(d-\underline{y})$, because it implies $d-\omega(p(k)+q(k))-(1-\omega) y>0$ for any $y \in[\underline{y}, \bar{y}]$. Similarly, the numerator will be negative if $p(k)+q(k)<d+\frac{1-\omega}{\omega}(d-\bar{y})$, because it implies $d-\omega(p(k)+q(k))-(1-\omega) y<0$ for any $y \in[\underline{y}, \bar{y}]$. This proves the statements regarding the full risk transfer in Propositions $3 \mathrm{a}$ and $3 \mathrm{~b}$.

\section{A.3.2 Transfer risk in the junior position}

For the strategy transferring the risk in the first-loss position, we have in Eq. (1) that

$$
x_{j, k}^{*}(y, r)= \begin{cases}\frac{\delta_{j, k}(r)-(1-\omega) y-r \omega(k+q(k))}{(1-r) \omega} & \text { if } y<y_{j, k}^{*}(r) ; \\ \frac{\delta_{j, k}(r)-(1-\omega) y-r \omega q(k)}{\omega} & \text { if } y \geq y_{j, k}^{*}(r),\end{cases}
$$

where $y_{j, k}^{*}(r)$ is the (unique) solution of $x_{j, k}^{*}\left(y_{j, k}^{*}(r), r\right)=k$, i.e.,

$$
y_{j, k}^{*}(r)=\frac{\delta_{j, k}(r)-\omega(r q(k)+k)}{1-\omega} .
$$


From (32), it follows that

$$
\frac{\partial x_{j, k}^{*}(y, r)}{\partial r}= \begin{cases}\frac{(1-r) \frac{\partial \delta_{j, k}(r)}{\partial r}+\delta_{j, k}(r)-\omega(k+q(k))-(1-\omega) y}{(1-r)^{2} \omega} & \text { if } y<y_{j, k}^{*}(r) \\ \frac{\frac{\partial \delta_{j, k}^{*}(r)}{\partial r}-\omega q(k)}{\omega} & \text { if } y \geq y_{j, k}^{*}(r) .\end{cases}
$$

To obtain the level of $\partial \delta_{j, k}(r) / \partial r$ in Eq. (34), we rewrite Eq. (7) as

$$
\begin{aligned}
\delta_{j, k}(r)-d= & \int_{0}^{y_{j, k}^{*}(r)} \int_{0}^{k} \phi^{Q}(x, y)\left[\delta_{j, k}(r)-\omega(x+r q(k))-(1-\omega) y\right] \mathrm{d} x \mathrm{~d} y \\
& +\int_{0}^{y_{j, k}^{*}(r)} \int_{k}^{x_{j, k}^{*}(y, r)} \phi^{Q}(x, y)\left[\delta_{j, k}(r)-\omega((1-r) x+r(k+q(k)))-(1-\omega) y\right] \mathrm{d} x \mathrm{~d} y \\
& +\int_{y_{j, k}^{*}(r)}^{\infty} \int_{0}^{x_{j, k}^{*}(y, r)} \phi^{Q}(x, y)\left[\delta_{j, k}(r)-\omega(x+r q(k))-(1-\omega) y\right] \mathrm{d} x \mathrm{~d} y
\end{aligned}
$$

Taking the implicit derivative of Eq. (35), while using $x_{j, k}^{*}\left(y_{j, k}^{*}(r), r\right)=k$ and $v_{j, k}\left(x_{j, k}^{*}(y, r), y, r\right)=\delta_{j, k}(r)$, gives

$$
\begin{aligned}
\frac{\partial \delta_{j, k}(r)}{\partial r}= & \int_{0}^{y_{j, k}^{*}(r)} \int_{0}^{k} \phi^{Q}(x, y)\left[\frac{\partial \delta_{j, k}(r)}{\partial r}-\omega q(k)\right] \mathrm{d} x \mathrm{~d} y \\
& +\int_{0}^{y_{j, k}^{*}(r)} \int_{k}^{x_{j, k}^{*}(y, r)} \phi^{Q}(x, y)\left[\frac{\partial \delta_{j, k}(r)}{\partial r}-\omega q(k)+\omega(x-k)\right] \mathrm{d} x \mathrm{~d} y \\
& +\int_{y_{j, k}^{*}(r)}^{\infty} \int_{0}^{x_{j, k}^{*}(y, r)} \phi^{Q}(x, y)\left[\frac{\partial \delta_{j, k}(r)}{\partial r}-\omega q(k)\right] \mathrm{d} x \mathrm{~d} y .
\end{aligned}
$$

Rewriting Eq. (36), while using the definition of $\pi_{j, k}^{Q}(r)$ in Eq. (8), gives

$$
\frac{\partial \delta_{j, k}(r)}{\partial r}=-\frac{\omega q(k) \pi_{j, k}^{Q}(r)-\omega \int_{0}^{y_{j, k}^{*}(r)} \int_{k}^{x_{j, k}^{*}(y, r)} \phi^{Q}(x, y)(x-k) \mathrm{d} x \mathrm{~d} y}{1-\pi_{j, k}^{Q}(r)} .
$$


Moreover, rewriting Eq. (35) with the definition of $\pi_{j, k}^{Q}(r)$ gives

$$
\begin{aligned}
\left(1-\pi_{j, k}^{Q}(r)\right) \delta_{j, k}(r)= & \left(1-\pi_{j, k}^{Q}(r)\right) d \\
& +\int_{0}^{y_{j, k}^{*}(r)} \int_{0}^{k} \phi^{Q}(x, y)[d-\omega(x+r q(k))-(1-\omega) y] \mathrm{d} x \mathrm{~d} y \\
& +\int_{0}^{y_{j, k}^{*}(r)} \int_{k}^{x_{j, k}^{*}(y, r)} \phi^{Q}(x, y)[d-\omega((1-r) x+r(k+q(k)))-(1-\omega) y] \mathrm{d} x \mathrm{~d} y \\
& +\int_{y_{j, k}^{*}(r)}^{\infty} \int_{0}^{x_{j, k}^{*}(y, r)} \phi^{Q}(x, y)[d-\omega(x+r q(k))-(1-\omega) y] \mathrm{d} x \mathrm{~d} y . \quad(38)
\end{aligned}
$$

Then, using Eqs. (37) and (38) in Eq. (34) gives, for $y<y_{j, k}^{*}(r)$,

$$
\begin{aligned}
\frac{\partial x_{j, k}^{*}(y, r)}{\partial r}=[ & \left(1-\pi_{j, k}^{Q}(r)\right)[d-(1-\omega) y-\omega(k+q(k))] \\
& +\int_{0}^{y_{j, k}^{*}(r)} \int_{0}^{k} \phi^{Q}(x, y)[d-\omega(x+q(k))-(1-\omega) y] \mathrm{d} x \mathrm{~d} y \\
& +\int_{0}^{y_{j, k}^{*}(r)} \int_{k}^{x_{j, k}^{*}(y, r)} \phi^{Q}(x, y)[d-\omega(k+q(k))-(1-\omega) y] \mathrm{d} x \mathrm{~d} y \\
& \left.+\int_{y_{j, k}^{*}(r)}^{\infty} \int_{0}^{x_{j, k}^{*}(y, r)} \phi^{Q}(x, y)[d-\omega(x+q(k))-(1-\omega) y] \mathrm{d} x \mathrm{~d} y\right] / \\
& {\left[\left(1-\pi_{j, k}^{Q}(r)\right) \omega(1-r)^{2}\right] . }
\end{aligned}
$$

The denominator of Eq. (39) is positive for any $r \in[0,1]$. Moreover, the numerator will be positive if $k+q(k)<d-\frac{1-\omega}{\omega}(\bar{y}-d)$, because it implies $d-(1-\omega) y-\omega(k+q(k))>0$ for any $y \in[\underline{y}, \bar{y}]$, and it implies $d-(1-\omega) y-\omega(x+q(k))>0$ for any $(x, y) \in[0, k] \times[\underline{y}, \bar{y}]$. Finally, $y<y_{j, k}^{*}(r)$ is implied by $k+q(k)<d-\frac{1-\omega}{\omega}(\bar{y}-d)$, because, from Eq. (33), $y<y_{j, k}^{*}(r)$ requires the weaker condition $k+r q(k)<\delta_{j, k}(r)-\frac{1-\omega}{\omega}\left(\bar{y}-\delta_{j, k}(r)\right)$ (this condition is weaker because $\delta_{j, k}(r) \geq d$ and $\left.0 \leq r \leq 1\right)$. This proves the statement regarding the increase in insolvency risk in Proposition 3a. 
Moreover, rewriting Eq. (36) gives,

$$
\begin{aligned}
\frac{\partial \delta_{j, k}(y, r)}{\partial r}=[ & \int_{0}^{y_{j, k}^{*}(r)} \int_{k}^{x_{j, k}^{*}(y, r)} \phi^{Q}(x, y)[x-\omega(k+q(k))] \mathrm{d} x \mathrm{~d} y \\
& -\omega q(k) \int_{0}^{y_{j, k}^{*}(r)} \int_{0}^{k} \phi^{Q}(x, y) \mathrm{d} x \mathrm{~d} y \\
& \left.-\omega q(k) \int_{y_{j, k}^{*}(r)}^{\infty} \int_{0}^{x_{j, k}^{*}(y, r)} \phi^{Q}(x, y) \mathrm{d} x \mathrm{~d} y\right] / \\
& {\left[1-\pi_{j, k}^{Q}(r)\right] . }
\end{aligned}
$$

The denominator of Eq. (40) is positive for any $r \in[0,1]$. Moreover, it can easily be verified in Eq. (32) that, if $k+q(k)>\delta_{j, k}(r)+\frac{1-\omega}{\omega}\left(\delta_{j, k}(r)-\underline{y}\right)$, then $x_{j, k}^{*}(y, r)<k+q(k)$ for any $y \in[\underline{y}, \bar{y}]$. This implies that both parts of the numerator in Eq. (40) are negative. As a consequence, $\partial \delta_{j, k}(r) / \partial r<0$ if $k+q(k)>\delta_{j, k}(r)+\frac{1-\omega}{\omega}\left(\delta_{j, k}(r)-\underline{y}\right)$. Finally, with $\partial \delta_{j, k}(r) / \partial r<0$, it is easily verified in Eq. (34) that $\partial x_{j, k}^{*}(y, r) / \partial r<0$ for any $y \in[\underline{y}, \bar{y}]$. This proves the statement regarding reduction in the probability of insolvency with the transfer of the risk in the senior position in Proposition $3 \mathrm{~b}$.

\section{A.3.3 Transfer risk in the senior position}

For the strategy transferring the risk in the senior position, we obtain from Eq. (1) that

$$
x_{s, k}^{*}(y, r)= \begin{cases}\frac{\delta_{s, k}(r)-(1-\omega) y-r \omega p(k)}{\omega} & \text { if } y<y_{s, k}^{*}(r) ; \\ \frac{\delta_{s, k}(r)-(1-\omega) y-r \omega(k-p(k))}{\omega(1-r)} & \text { if } y \geq y_{s, k}^{*}(r),\end{cases}
$$

where $y_{s, k}^{*}(r)$ is the (unique) solution of $x_{s, k}^{*}\left(y_{s, k}^{*}(r), r\right)=k$, i.e.,

$$
y_{s, k}^{*}(r)=\frac{\delta_{s, k}(r)-\omega(r p(k)+(1-r) k)}{1-\omega} .
$$


From (41), it follows that

$$
\frac{\partial x_{s, k}^{*}(y, r)}{\partial r}= \begin{cases}\frac{\frac{\partial \delta_{s, k}(r)}{\partial r}-\omega(k-p(k))}{\omega} & \text { if } y<y_{s, k}^{*}(r) ; \\ \frac{(1-r) \frac{\partial \delta_{s, k}(r)}{\partial r}+\delta_{s, k}(r)-\omega p(k)-(1-\omega) y}{(1-r)^{2} \omega} & \text { if } y \geq y_{s, k}^{*}(r) .\end{cases}
$$

To obtain the level of $\partial \delta_{s, k}(r) / \partial r$ in Eq. (43), we rewrite Eq. (7) as

$$
\begin{aligned}
\delta_{s, k}(r)-d= & \int_{0}^{y_{s, k}^{*}(r)} \int_{0}^{k} \phi^{Q}(x, y)\left[\delta_{s, k}(r)-\omega((1-r) x+r p(k))-(1-\omega) y\right] \mathrm{d} x \mathrm{~d} y \\
& +\int_{0}^{y_{s, k}^{*}(r)} \int_{k}^{x_{s, k}^{*}(y, r)} \phi^{Q}(x, y)\left[\delta_{s, k}(r)-\omega(x-r(k-p(k)))-(1-\omega) y\right] \mathrm{d} x \mathrm{~d} y \\
& +\int_{y_{s, k}^{*}(r)}^{\infty} \int_{0}^{x_{s, k}^{*}(y, r)} \phi^{Q}(x, y)\left[\delta_{s, k}(r)-\omega((1-r) x+r p(k))-(1-\omega) y\right] \mathrm{d} x \mathrm{~d} y .
\end{aligned}
$$

Taking the implicit derivative of Eq. (44), while using $x_{s, k}^{*}\left(y_{s, k}^{*}(r), r\right)=k$ and $v_{s, k}\left(x_{s, k}^{*}(y, r), y, r\right)=\delta_{s, k}(r)$, gives

$$
\begin{aligned}
\frac{\partial \delta_{s, k}(r)}{\partial r}= & \int_{0}^{y_{s, k}^{*}(r)} \int_{0}^{k} \phi^{Q}(x, y)\left[\frac{\partial \delta_{s, k}(r)}{\partial r}-\omega(p(k)-x)\right] \mathrm{d} x \mathrm{~d} y \\
& +\int_{0}^{y_{s, k}^{*}(r)} \int_{k}^{x_{s, k}^{*}(y, r)} \phi^{Q}(x, y)\left[\frac{\partial \delta_{s, k}(r)}{\partial r}-\omega(p(k)-k)\right] \mathrm{d} x \mathrm{~d} y \\
& +\int_{y_{s, k}^{*}(r)}^{\infty} \int_{0}^{x_{s, k}^{*}(y, r)} \phi^{Q}(x, y)\left[\frac{\partial \delta_{s, k}(r)}{\partial r}-\omega(p(k)-x)\right] \mathrm{d} x \mathrm{~d} y .
\end{aligned}
$$

Rewriting Eq. (45), while using the definition of $\pi_{s, k}^{Q}(r)$ in Eq. (8), gives

$$
\begin{aligned}
& \frac{\partial \delta_{s, k}(r)}{\partial r}=\left[\omega \pi_{s, k}^{Q}(r)(k-p(k))-\omega \int_{0}^{y_{s, k}^{*}(r)} \int_{0}^{k} \phi^{Q}(x, y)(k-x) \mathrm{d} x \mathrm{~d} y\right. \\
&\left.-\omega \int_{y_{s, k}^{*}(r)}^{\infty} \int_{0}^{x_{s, k}^{*}(y, r)} \phi^{Q}(x, y)(k-x) \mathrm{d} x \mathrm{~d} y\right] / \\
& {\left[1-\pi_{s, k}^{Q}(r)\right] . }
\end{aligned}
$$


Then, using Eqs. (44) and (45) in Eq. (43) gives, for $y \geq y_{s, k}^{*}(r)$,

$$
\begin{aligned}
\frac{\partial x_{s, k}^{*}(r)}{\partial r}=[ & \left(1-\pi_{s, k}^{Q}(r)\right)[d-\omega p(k)-(1-\omega) y] \\
& +\int_{0}^{y_{s, k}^{*}(r)} \int_{0}^{k} \phi^{Q}(x, y)[d-\omega p(k)-(1-\omega) y] \mathrm{d} x \mathrm{~d} y \\
& +\int_{0}^{y_{s, k}^{*}(r)} \int_{k}^{x_{s, k}^{*}(r)} \phi^{Q}(x, y)[d-\omega(x+k-p(k))-(1-\omega) y] \mathrm{d} x \mathrm{~d} y \\
& \left.+\int_{y_{s, k}^{*}(r)}^{\infty} \int_{0}^{x_{s, k}^{*}(y, r)} \phi^{Q}(x, y)[d-\omega p(k)-(1-\omega) y] \mathrm{d} x \mathrm{~d} y\right] / \\
& {\left[\omega\left(1-\pi_{s, k}^{Q}(r)\right)(1-r)^{2}\right] . }
\end{aligned}
$$

The numerator of Eq. (47) is positive for any $r \in[0,1]$. It can easily be verified that each of the parts in the numerator is negative if

$$
p(k)>d+\frac{1-\omega}{\omega}(d-\underline{y})
$$

since this implies $d<\omega p(k)-(1-\omega) y$ for any $y \in[\underline{y}, \bar{y}]$ (note that $x+k-p(k)>p(k)$ for any $x \geq k$ ). However, Eq. (47) only holds true for $y \geq y_{s, k}^{*}(r)$, which is implied by

$$
(1-r) k+r p(k)>\delta_{s, k}(r)+\frac{1-\omega}{\omega}\left(\delta_{s, k}(r)-\underline{y}\right) .
$$

The conditions in (48) and (49) jointly hold true if $p(k)>\delta_{s, k}(r)+\frac{1-\omega}{\omega}\left(\delta_{s, k}(r)-\underline{y}\right)$, since $k>$ $p(k)$ and $d \leq \delta_{s, k}(r)$. This proves the statement regarding the reduction in the probability of insolvency as a consequence of the transfer of the risk in the senior position in Proposition $3 b$. 
Moreover, using Eq. (46) in Eq. (43) gives, for $y<y_{s, k}^{*}(r)$,

$$
\begin{aligned}
\frac{\partial x_{s, k}^{*}(r)}{\partial r}=[ & (k-p(k))-\int_{0}^{y_{s, k}^{*}(r)} \int_{0}^{k} \phi^{Q}(x, y)(k-x) \mathrm{d} x \mathrm{~d} y \\
& \left.-\int_{y_{s, k}^{*}(r)}^{\infty} \int_{0}^{x_{s, k}^{*}(y, r)} \phi^{Q}(x, y)(k-x) \mathrm{d} x \mathrm{~d} y\right] / \\
& {\left[1-\pi_{s, k}^{Q}(r)\right] . }
\end{aligned}
$$

With the definition of the pricing of the risk premium by depositors in (10), we have from (47) that, for $y \geq y_{s, k}^{*}(r)$,

$$
\frac{\partial x_{s, k}^{*}(r)}{\partial r}=\frac{(k-p(k))-\left(k-p^{Q}(k)\right)+\int_{y_{s, k}^{*}(r)}^{\infty} \int_{x_{s, k}^{*}(y, r)}^{k} \phi^{Q}(x, y)(k-x) \mathrm{d} x \mathrm{~d} y}{1-\pi_{s, k}^{Q}(r)} .
$$

The denominator of this derivative is positive, as is the double integral in the numerator. As a consequence, Eq. (51) must be positive if $(k-p(k)) \geq\left(k-p^{Q}(k)\right)$. Hence, $\partial x_{s, k}^{*}(r) / \partial r>0$ for $y \geq y_{s, k}^{*}(r)$, where the latter is implied by $\delta_{s, k}(r)+\frac{1-\omega}{\omega}\left(\bar{y}-\delta_{s, k}(r)\right)>(1-r) k+r p(k)$. Since $k \geq(1-r) k+r p(k)$ for any $r \in[0,1]$, this proves the statement regarding the increase in insolvency risk of the transfer of the risk in the senior position in Proposition 3a. 


\section{References}

F. Allen and E. Carletti. Credit Risk Transfer and Contagion. Journal of Monetary Economics, 53:89-111, 2006.

L.M. Benveniste and A.N. Berger. Securitization with Recourse: An Instrument that Offers Uninsured Bank Depositors Sequential Claims. Journal of Banking \& Finance, 11(3): 403-424, 1987.

A.W.A. Boot and A.V. Thakor. Security Design. Journal of Finance, 48(4):1349-1378, 1993.

B. Casu, A. Clare, A. Sarkisyan, and S. Thomas. Securitization and Bank Performance. Journal of Money, Credit and Banking, 45(8):1617-1658, 2013.

A.S. Cebenoyan and P.E. Strahan. Risk Management, Capital Structure and Lending at Banks. Journal of Banking \& Finance, 28(1):19-43, 2004.

V. Cerasi and J.C. Rochet. Rethinking the Regulatory Treatment of Securitization. Journal of Financial Stability, 10:20-31, 2014.

Y.-S. Chan and G. Kanatas. Asymmetric Valuations and the Role of Collateral in Loan Agreements. Journal of Money, Credit and Banking, 17(1):84-95, 1985.

C.-P. Chang and S. Chen. Government Capital Injection, Credit Risk Transfer, and Bank Performance During a Financial Crisis. Economic Modelling, 53:477-486, 2016.

G. Chiesa. Optimal Credit Risk Transfer, Monitored Finance, and Banks. Journal of Financial Intermediation, 17:464-477, 2008.

Committee on Economic and Monetary Affairs. Report on the Proposal for a Regulation of the European Parliament and of the Council Laying Down Common Rules on Securitisation etc. European Parliament, 2016.

P. DeMarzo and D. Duffie. A Liquidity-based Model of Security Design. Econometrica, 67 (1):65-99, 1999. 
P.M. DeMarzo. The Pooling and Tranching of Securities: A Model of Informed Intermediation. Review of Financial Studies, 18(1):1-35, 2005.

D. Duffie, A. Eckner, G. Horel, and L. Saita. Frailty Correlated Default. Journal of Finance, 64(5):2089-2123, 2009.

I. Fender and J. Mitchell. The Future of Securitisation: How to Align Incentives? BIS Quarterly Review, (September):27-43, 2009.

G. Franke and J.P. Krahnen. Default Risk Sharing Between Banks and Markets: The Contribution of Collateralized Debt Obligations. In M. Carey and R.M. Stulz, editors, The Risks of Financial Institutions, pages 603-634. University of Chicago Press, 2007.

N. Gennaioli, A. Shleifer, and R. Vishny. Neglected Risks, Financial Innovation, and Financial Fragility. Journal of Financial Economics, 104(3):452-468, 2012.

G. Gorton and G. Pennacchi. Financial Intermediaries and Liquidity Creation. Journal of Finance, 45(1):49-71, 1990.

G. Gorton and G. Pennacchi. Banks and Loan Sales: Marketing Nonmarketable Assets. Journal of Monetary Economics, 35:389-411, 1995.

S.I. Greenbaum and A.V. Thakor. Bank Funding Modes: Securitization versus Deposits. Journal of Banking \& Finance, 11(3):379-401, 1987.

G. Guo and H.M. Wu. A Study on Risk Retention Regulation in Asset Securitization Process. Journal of Banking \& Finance, 45:61-71, 2014.

J. Kiff and M. Kisser. A Shot at Regulating Securitizations. Journal of Financial Stability, 10:32-49, 2014.

D.N. Lal. A Note on a Form of Tchebycheff's Inequality for Two or More Variables. Indian Journal of Statistics, 15(3):317-320, 1955. 
H.T.T. Le, R.P. Narayanan, and L. van Vo. Has the Effect of Asset Securitization on Bank Risk Taking Behavior Changed? Journal of Financial Services Research, 49(1):39-64, 2016.

L.J. Lockwood, R.C. Rutherford, and M.J. Herrera. Wealth Effects of Asset Securitization. Journal of Banking $\mathcal{G}$ Finance, 20(1):151-164, 1996.

H. Pagès. Bank Monitoring Incentives and Optimal ABS. Journal of Financial Intermediation, 22(1):30-54, 2013.

G.G. Pennacchi. Loan Sales and the Cost of Bank Capital. Journal of Finance, 43(2): 375-396, 1988.

T.J. Riddiough. Optimal Design and Governance of Asset-Backed Securities. Journal of Financial Intermediation, 6:121-152, 1997.

A. Sarkisyan and B. Casu. Retained Interests in Securitizations and Implications for Bank Solvency. ECB Working Paper, 1538, 2013.

S. Shaffer. Pooling Intensifies Joint Failure Risk. Research in Financial Services: Private and Public Policy, 6:249-280, 1994.

H.S. Shin. Securitisation and Financial Stability. Economic Journal, 119(536):309-332, 2009.

L.G. Telser. Safety First and Hedging. Review of Economic Studies, 23(1):1-16, 1955.

H. Thomas. Effects of Asset Securitization on Seller Claimants. Journal of Financial Intermediation, 10(3-4):306-330, 2001.

R. Trapp and G.N.F. Weiß. Derivatives Usage, Securitization, and the Crash Sensitivity of Bank Stocks. Journal of Banking \&3 Finance, 71:183-205, 2016.

A. Uhde and T.C. Michalak. Securitization and Systematic Risk in European Banking: Empirical Evidence. Journal of Banking \& Finance, 34(12):3061-3077, 2010. 
M.R.C. Van Oordt. Securitization and the Dark Side of Diversification. Journal of Financial Intermediation, 23(2):214-231, 2014.

W. Wagner. The Liquidity of Bank Assets and Banking Stability. Journal of Banking \& Finance, 31(1):121-139, 2007.

W. Wagner. Diversification at Financial Institutions and Systemic Crises. Journal of Financial Intermediation, 19(3):373-386, 2010.

W. Wagner and I.W. Marsh. Credit Risk Transfer and Financial Sector Stability. Journal of Financial Stability, 2:173-193, 2006. 